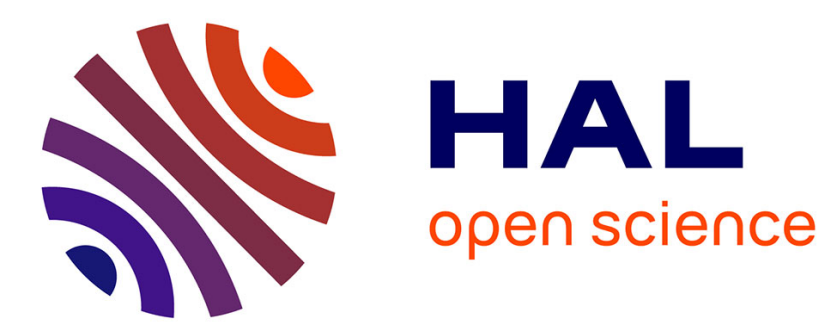

\title{
Oxidation of laccase for improved cathode biofuel cells performances
}

Meihui Zheng, Sophie Griveau, Christine Dupont-Gillain, Michel J Genet, Claude Jolivalt

\section{- To cite this version:}

Meihui Zheng, Sophie Griveau, Christine Dupont-Gillain, Michel J Genet, Claude Jolivalt. Oxidation of laccase for improved cathode biofuel cells performances. Bioelectrochemistry, 2015, 106 (Part A), pp.77-87. 10.1016/j.bioelechem.2015.06.004 . hal-01172482

\section{HAL Id: hal-01172482 https://hal.sorbonne-universite.fr/hal-01172482}

Submitted on 7 Jul 2015

HAL is a multi-disciplinary open access archive for the deposit and dissemination of scientific research documents, whether they are published or not. The documents may come from teaching and research institutions in France or abroad, or from public or private research centers.
L'archive ouverte pluridisciplinaire HAL, est destinée au dépôt et à la diffusion de documents scientifiques de niveau recherche, publiés ou non, émanant des établissements d'enseignement et de recherche français ou étrangers, des laboratoires publics ou privés. 


\title{
Oxidation of laccase for improved cathode biofuel cells performances
}

\author{
Meihui Zheng ${ }^{\mathrm{a}}$, Sophie Griveau ${ }^{\mathrm{b}}$, Christine Dupont-Gillain ${ }^{\mathrm{c}}$, Michel J. Genet ${ }^{\mathrm{c}}$, Claude \\ Jolivalt $^{\mathrm{a}, \mathrm{d}, \mathrm{e},{ }^{*}}$ \\ a Laboratory Charles Friedel, CNRS UMR 7223, Chimie ParisTech, 11 rue Pierre et Marie \\ Curie, F-75231 Paris cedex 05, France. \\ ${ }^{b}$ PSL Research University, Chimie ParisTech, Ecole Nationale Supérieure de Chimie de \\ Paris, Unité de Technologies Chimiques et Biologiques pour la Santé, UMR 8258, INSERM \\ 1022, 11 rue Pierre et Marie Curie, F-75231 Paris cedex 05, France. \\ ${ }^{\mathrm{c}}$ Institute of Condensed Matter and Nanosciences, Université Catholique de Louvain, Croix \\ du Sud 1 Box L7.04.01, B-1348 Louvain-la-Neuve, Belgium \\ ${ }^{d}$ CNRS UMR 7197, Laboratoire de Réactivité de Surface, F-75005 Paris, France \\ e Sorbonne Universités, UPMC Univ Paris 06, UMR 7197, Laboratoire de Réactivité de \\ Surface, F-75005 Paris, France
}

*Corresponding author: Claude Jolivalt, Tel: +33144276013, Email: claude.jolivalt@upmc.fr, Postal address : Laboratoire de Réactivité de Surface, Université Pierre et Marie Curie, 3 rue Galilée, F-94200 Ivry sur Seine, France.

\section{Email addresses}

Sophie Griveau : sophie.griveau@chimie-paristech.fr

Christine Dupont-Gillain : christine.dupont@uclouvain.be

Michel J. Genet : michel.genet@uclouvain.be

Meihui Zheng : meihui.zheng2809@gmail.com

\begin{abstract}
Graphite rods were modified by substituted aryldiazonium salts allowing subsequent laccase immobilisation and direct electron transfer at the cathode. Two covalent enzyme immobilisation methods were performed with carboxy and amino substituted grafted groups, either via the formation of an amide bond or a Schiff base between the glycosidic groups of the enzyme and the amino groups on the electrode surface, respectively. Laccase adsorption efficiency was consistently compared to the covalent attachment method on the same carbon surface, showing that the latter method led to a higher immobilization yield when the electrode surface was functionalized with carboxylic groups, as shown from both laccase activity measurement toward an organic reducing substrate, ABTS, and quantitative XPS analysis. Both analytical methods led to similar laccase surface coverage estimation. From activity measurements, when laccase was covalently immobilized on the electrode functionalized with carboxylic groups, the surface coverage was found to be $43 \pm 2 \%$ whereas it was only $10 \pm 3 \%$ when laccase was adsorbed. Biocatalyzed dioxygen reduction current was also higher in case of covalent immobilization. For the first time, oxidized laccase performances were compared to unmodified laccase, showing significant improved efficiency when using oxidized laccase: the current obtained with oxidized laccase was $141 \pm 37 \mu \mathrm{Acm}^{-2}$ compared to $28 \pm 6 \mu \mathrm{Acm}^{-2}$ for unmodified laccase after covalent immobilization of the enzyme on a graphite electrode functionalized with carboxylic groups.
\end{abstract}

Keywords: biofuel cell; direct electron transfer; oxidized laccase; biocathode; diazonium salt; biocatalytic dioxygen reduction; XPS 


\section{Introduction}

Due to the prospect of the starvation of traditional fuel sources, alternative sources of sustainable electrical energy, including biofuel cells (BFC), have become a strategic research field [1] [2] [3] [4] [5]. Enzymatic biofuel cells are designed to generate electric current from bioelectrocatalyzed chemical redox transformations. The oxidation of the fuel, typically hydrogen or an organic compound such as glucose takes place at the anode while the cathode is responsible for the reduction of an oxidant such as dioxygen. These redox reactions are biocatalyzed by different enzymes such as glucose oxidase or dehydrogenase at the anode, bilirubine oxidase [6] , laccase or tyrosinase at the cathode and can occur directly at the electrodes or need the use of redox mediators that act as electron shuttle between the enzyme and the electrode.

Biomolecule immobilisation is a crucial process in many biotechnological applications, including the biofuel cells field. The immobilisation method should not only guarantee that the enzyme is retained on the support, but also should ensure a close proximity between the enzyme active site and the electrode surface in order to obtain an efficient electron transfer. Moreover, the immobilization of the enzyme on the surface should preserve its activity, ie should not affect the 3D conformation of active sites. Over the past decade, the bulk of the research in enzymatic fuel cells has been directed toward enzyme/electrode integration methods that alleviate the power density limitations resulting from low electron transfer rate from the enzyme active site to the electrode[3]. Together with enhanced long term operational stability, this point is a key challenge in the engineering of efficient electrochemical devices such as biofuel cells or biosensors [7] [8] [9] [10] [11] [12].

A simple immobilisation method is physical adsorption. This technique, based on weak interactions (e.g. hydrogen bonds, electrostatic interactions and Van der Waals forces) usually does not induce significant enzyme structure modification that would affect its activity, especially when the surface is hydrophilic but again enzyme desorption cannot be excluded. Recently, Cosnier et al used an original mechanical confinement of enzymes inside the electrodes by compressing some graphite [13] or CNT[14], the biocatalyst and eventually redox mediator mixture. Such a biofuel cell design using naphtoquinone-mediated oxidation of glucose by GOx and direct electron transfer (DET) using laccase at the cathode exhibited a power output of $1.54 \mathrm{mWcm}^{-2}$ and current densities of $4.47 \mathrm{mAcm}^{-2}$, the highest reported to date, to the best of our knowledge [15]. The device was successfully implanted in a rat abdominal cavity and achieved in vivo enough current densities that an external capacitor could be charged to generate enough power to act as a sole power source for a light-emitting diode [16] [17]. Interestingly, at the same period, Pankratov et al. also described a hybrid self charging electrochemical biocapacitor including an enzymatic fuel cell $[18,19]$. However, as Reuillard and coworkers [20] suggested in their conclusion, optimisation of the laccase wiring at the biocathode is still to be improved. Indeed, comparison between the highest currents obtained by DET with non orientated laccase compressed with CNTs in 3D structures and covalently immobilized enzyme shows that in the first case, a large amount of laccase, typically a few to fifteen milligrams [20] is needed whereas about four orders of magnitude lower amounts have been used to generate a power density only ten fold lower [21] or one hundred fold lower [22] on similar electrode area after laccase covalent grafting. One reason for the higher currents obtained with the enzyme covalent grafting method could result from the amino acid composition of laccases from Trametes versicolor that contain 45 basic residues distributed all over the tridimensionnal structure but only 5 lysine side chains among 499 total amino acids [23]. Enzyme grafting via its lysine groups thus could lead to a better orientation control of the enzyme than via its carboxylic groups.

However, covalent immobilization method requires the presence of functional groups on the electrode surface to allow a covalent bonding with reactive groups on the protein, e.g. mostly carboxylic and amino groups. Among the methods developed to covalently bind chemical groups to carbon electrodes, a protocol initially proposed by Pinson et al.[24] has emerged. It involves the grafting of functionalized aryl groups via the electrochemical reduction of aryldiazonium salts bearing a wide range of functional groups. This easy-to-use 
method results in highly stable layers [25] [26] and can be applied for microscale devices [27] [28]. In recent studies [29] [26], gold, graphite and glassy-carbon (GC) electrodes were functionalised using aryldiazonium salts bearing carboxylic acid groups, with subsequent grafting of GOx on the modified electrode. The modified electrodes retained much of their activity after six weeks, while control electrodes prepared by depositing the crosslinker and GOx directly onto the GC had lost all activity within only one week [29]. The diazonium electroreduction method also allowed the functionalization of graphite carbon with amino groups. In case of laccase, this aniline derivative mimics a potential enzyme reducing substrate, thus allowing molecular recognition and specific interactions to control the laccase orientation on the surface, which is a key element for the fabrication of bioelectrodes with high electron transfer efficiency [22,30]. Moreover, the functionalization method by diazonium reduction allows a direct electron transfer between the electrode and the enzyme, as shown for glucose oxidase [29] and laccase [21]. Diazonium electrografting on carbon thus appears as a versatile functionalization method for subsequent enzyme immobilisation and DET. Because different functional groups can be grafted on the stable phenyl layer, it provides a useful scaffold for consistent study of the effect of enzyme orientation on the electrode surface.

In this work, functionalization of graphite carbon by aryldiazonium salt electrografting has been performed to immobilise fungal laccase from Trametes versicolor on graphite rods. Both adsorption or/and covalent grafting were performed on functionalized surfaces according to the same protocol, thus allowing accurate comparison between these two immobilization methods in terms of enzyme loading and electron transfer efficiency. In addition, the influence of the enzyme orientation induced by covalent grafting either via its carboxylic or amine residues has been studied on electrodes functionalized using similar methods, ie electrodeposition of diazonium salts. As an alternative grafting method to the formation of a peptidic bond, laccase was also cross-linked via its oxidized oligosaccharides. This method indeed was reported to lead to efficient wired laccase[31] and glucose oxidase[32] electrodes. However, the interest of using oxidized laccase as a biocatalyst in a biofuel cell without grafting it via its glycosidic groups has not been demonstrated yet, to the best of our knowledge. This issue will be addressed by comparing immobilization of both unmodified and oxidized laccase on electrodes functionalized with carboxylic groups. All functionalized electrodes have been characterised by XPS, before and after enzyme immobilization. The comparison between the immobilization procedures was performed by measuring both the enzymatic activity of the bioelectrodes and their catalytic efficiency for dioxygen reduction.

\section{Materials and methods}

\subsection{Reagents}

4-Aminobenzoic acid, 4-nitrobenzenediazonium tetrafluoroborate, tetrabutylammonium tetrafluoroborate, 2,2'-azobis(3-ethylbenzothiazole-6-sulfonic acid) (ABTS), toluidine blue-O (TBO) and N-hydroxysuccinimide (NHS) were purchased from Sigma-Aldrich. 2- 1-(3dimethylaminopropyl)-3-ethylcarbodiimide (EDC) was from Fluka. Buffer solutions were prepared with disodium hydrogenophosphate (Acros Organics), sodium dihydrogenophosphate, sodium acetate and acetic acid (Prolabo) in deionized water (Milli-Q grade, Millipore). Sodium perchlorate (Sigma-Aldrich) was used as electrolyte.

\section{Diazotation of 4-aminobenzoic acid}

$4 \mathrm{~mL}$ of tetrafluoroboric acid was cooled in an ice bath to $5^{\circ} \mathrm{C}$ before adding $4.10^{-3}$ mole of 4aminobenzoic acid. Following the addition, the temperature of the solution was maintained at $5^{\circ} \mathrm{C}$ for 20 minutes. A yellow precipitate formed during the slow addition of $4.510^{-3}$ moles of sodium nitrite. The diazonium salt was succion filtered and washed with cold ether. The solid was then dissolved in less than $5 \mathrm{~mL}$ methanol and crystallized by ether addition. 


\subsection{Enzyme}

Laccase was produced from Trametes versicolor (ATCC 32745) as previously described[33]. Purified laccase (around $900 \mathrm{UmL}^{-1}$ and $3 \mathrm{mg}$ total protein $\mathrm{mL}^{-1}$ ) was stored at $-20{ }^{\circ} \mathrm{C}$ in 50 $\mathrm{mM}$ phosphate buffer at $\mathrm{pH} 6.8$, where the stability of the enzyme is maximal in presence of glycerol ( $15 \% \mathrm{v} / \mathrm{v}$ final).

\subsection{Electrochemical functionalization of the carbon electrode}

\subsubsection{Electrodes materials}

$7 \mathrm{~mm}$ diameter spectrographic Carbon-Graphite rods (Mersen, France) were used. Prior to surface modification the carbon electrodes were polished with SiC paper (Buehler, Germany) with grit sizes 80 , cleaned with Milli-Q water and dried by filtered compressed air. The roughness $(\mathrm{Ra})$ of the resulting carbon surface was approximately $2500( \pm 300) \mathrm{nm}$. The geometric area of the carbon surface in contact with the electrolyte was $0.38 \mathrm{~cm}^{2}$.

\subsubsection{Functionalization of electrode surface and surface characterization}

Electrochemical modification

Carbon surfaces were functionalised by a diazonium cation electrochemical reduction procedure developed by Pinson and co-workers [24,34] and leading to the covalent attachment of aromatic groups onto the carbon surface.

a- Functionalization with amino groups. In a fisrt step, 4-nitrobenzene diazonium tetrafluoroborate (2 or $5 \mathrm{mM}$ ) electrochemical reduction was performed in anhydrous acetonitrile at electrode surface. Then cyclic voltammetry was perfomed from 0.8 to -0.2 V/SCE at a scan rate of $50 \mathrm{mVs}^{-1}$ in deaerated solution. In a second step, the nitro groups of the attached phenyl rings were reduced by one cycle from 0 to $-1.40 \mathrm{~V} / \mathrm{SCE}$ at $10 \mathrm{mVs}^{-1}$ in $0.1 \mathrm{M}$ deaerated potassium chloride solution using an ethanol/water (1:9) mixture as a solvent.

b- Functionalization with carboxylic groups. Two procedures were used. The first method consisted in dissolving 4-carboxybenzene diazonium salt $(5 \mathrm{mM})$ in $0.1 \mathrm{M}$ sulphuric acid in the electrochemical cell and the second one in generating the diazonium salt in situ in the cell from reaction of sodium nitrite and 4-aminobenzoic acid. In the latter case, a total of 1.5 $\mathrm{mL}$ of $0.1 \mathrm{M} \mathrm{NaNO}_{2}$ (one 4-aminobenzoic acid equivalent) was added to the electrolytic solution containing $5 \mathrm{mM}$ 4-aminobenzoic acid and $0.5 \mathrm{M} \mathrm{HCl}$ under mixing. The final volume of the solution was $30 \mathrm{~mL}$. The mixture was left to react at $4^{\circ} \mathrm{C}$ for about 15 minutes prior to the electrochemical functionalization[35]. For both methods, the solution was deaerated for 15 minutes before the potential was cycled one time between 0.5 and $-0.6 \mathrm{~V}$ (vs SCE) at 50 $\mathrm{mVs}^{-1}$ to perform the diazonium cation reduction. Following the modification, the carbon electrodes were rinsed thoroughly with distilled water to remove unbound molecules.

c- Determination of the carboxylic group densities using TBO:

The amount of $\mathrm{COOH}$ was determined using the toluidine blue (TBO) method[36]. Functionalised carbon rod was placed in $1 \mathrm{~mL}$ of TBO solution $\left(5.10^{-4} \mathrm{M}\right.$ in $\left.\mathrm{NaOH}, \mathrm{pH} 10\right)$ during 6 hours under mixing. After TBO binding, the supernatant was removed and the stained carbon surface was washed with $\mathrm{NaOH}$ solution $(\mathrm{pH} 10)$ and pure water for two times. $150 \mu \mathrm{L}$ of $50 \%$ acetic acid was added to remove the TBO dye from the carboxyl groups on the surfaces of carbon rods during $10 \mathrm{~min}$. The optical density of the solution was measured at $633 \mathrm{~nm}$. The concentration of released TBO was determined using a calibration plot. The concentration of the carboxyl groups on the surface was calculated based on the assumption that 1 mole of TBO has complexed exactly with 1 mole of carboxylic groups.

\subsection{Laccase oxidation}

We followed glycoprotein oxidation procedure described in the literature[37]. Briefly, $100 \mu \mathrm{L}$ of freshly prepared $0.1 \mathrm{M}$ sodium periodate in water (final concentration $5 \mathrm{mM}$ ) were rapidly mixed to $1.9 \mathrm{~mL}$ of a $75 \mathrm{U} / \mathrm{mL}$ purified laccase solution in $10 \mathrm{mM}$ phosphate buffer $(\mathrm{pH} 7)$. 
After 30 minutes in darkness at room temperature, the sodium periodate was removed by gel filtration on a PD10 chromatography column equilibrated with $10 \mathrm{mM}$ phosphate buffer $(\mathrm{pH} 7)$. The active fractions were pooled and concentrated over an Amicon YM30 ultrafiltration membrane to reach $100 \mathrm{U} / \mathrm{mL}$.

\subsection{Laccase immobilization on the electrodes}

The laccase was covalently immobilized on functionalised carbon electrodes using suitable procedure for each carbon functionalization (with amino or carboxy groups).

For carbon functionalised with amino groups, $10 \mu \mathrm{L}$ of laccase solution $\left(1 \mu \mathrm{g} \mathrm{LL}^{-1}, 2 \mathrm{U}\right.$ activity) prepared in $10 \mathrm{mM}$ phosphate buffer ( $\mathrm{pH}$ 7.0) was deposited on top of the electrode and allowed to settle for 20 min in order to induce the protein adsorption and orientation on the surface. Then $4.5 \mu \mathrm{L}$ of a $20 \mathrm{mM} \mathrm{NHS}$ solution (in $10 \mathrm{mM}$ phosphate buffer, $\mathrm{pH} 7.0$ ) and $5.5 \mu \mathrm{L}$ of a $40 \mathrm{mM}$ EDC solution (in $10 \mathrm{mM}$ phosphate buffer, $\mathrm{pH}$ 7.0) were added. The carboxylic groups activation and subsequent covalent immobilization of the enzyme was allowed for $2 \mathrm{~h}$ at ambient temperature.

In case of electrodes functionalised with carboxylic groups, the EDC/NHS mixture was first deposited on the electrode in order to activate the carboxylic groups, then after $20 \mathrm{~min}$, the protein solution was added.

Finally, the modified electrodes were soaked 3 times in the phosphate buffer solution $(10 \mathrm{mM}$, $\mathrm{pH} \mathrm{7.0)}$ for $30 \mathrm{~min}$ with stirring to remove any adsorbed laccase. The same procedure in the absence of EDC/NHS was performed to immobilize laccase by physical adsorption.

\subsection{Determination of the immobilized laccase activity:}

The activity of the immobilized laccase was spectrophotometrically determined at $420 \mathrm{~nm}$ with 2,2'-azobis(3-ethylbenzothiazole-6-sulfonic acid) (ABTS) as substrate. The electrode was soaked into $2 \mathrm{~mL}$ of citrate phosphate buffer $(25 \mathrm{mM}, \mathrm{pH}=3.0)$ containing $1 \mathrm{mM}$ ABTS, at $30^{\circ} \mathrm{C}$. The formation of ABTS radicals was recorded by measuring the optical density (A) at $420 \mathrm{~nm}$ during one minute. The concentration of ABTS radical in the solution, $\mathrm{c}\left(\mathrm{moll}^{-1}\right)$, was calculated using the Beer-Lambert relationship, $A=\varepsilon \times \mathrm{I} \times \mathrm{c}$, with $A$, the measured absorbance (no unit), $\varepsilon^{420 \mathrm{~nm}}=36000 \mathrm{~L} \mathrm{~mol}^{-1} \mathrm{~cm}^{-1}[38]$ and $\mathrm{l}=1 \mathrm{~cm}$. One unit of activity (U) is the amount of enzyme that catalyzed the formation of $1 \mu \mathrm{mol}$ of ABTS radical $/ \mathrm{min}$. The immobilized laccase activity Ac ( $U$ Laccase), was then determined as follows $A c=5.56 \times 10^{-}$ ${ }^{2} \Delta \mathrm{A} / \Delta \mathrm{t}$ with $\Delta \mathrm{A} / \Delta \mathrm{t}$ : slope of absorbance as a function of time (min). Activity measurements were performed at least two times for each immobilization procedure tested.

2.7. Electrochemical measurements: study of modified electrode performance towards dioxygen reduction

Cyclic voltammetry was carried out with a Princeton Applied Research Model 263A Potentiostat/Galvanostat in an electrochemical cell using three electrodes: the carbon working electrode, a saturated calomel electrode (SCE) was used as a reference and a platinum wire as the counter electrode. The three-electrode system was placed in $30 \mathrm{~mL}$ of

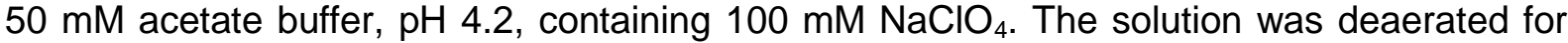
15 min with pure $\mathrm{N}_{2}$ gas which was kept flowing over the solution during the electrochemical measurements in the absence of oxygen. The potential was cycled between 0.9 and $-0.3 \mathrm{~V}$ (vs SCE) at $10 \mathrm{mVs}^{-1}$. The solution was then aerated for $10 \mathrm{~min}$ and cyclic voltammetry response in the presence of dioxygen was recorded in the same conditions. All the tests were conducted at room temperature. The current output values were determined at a potential of $0.2 \mathrm{~V}$ (vs SCE) after deduction of the current recorded at the same potential under nitrogen atmosphere. Electrochemical measurements were repeated two times for adsorbed laccase and three to five times for covalently immobilized enzyme with independantly prepared electrodes.

\subsection{X-ray photoelectron spectroscopy (XPS)}


X-ray photoelectron spectroscopy (XPS) analyses were performed on a Kratos Axis Ultra spectrometer (Kratos Analytical - Manchester - UK) equipped with a monochromatized aluminium X-ray source (powered at $10 \mathrm{~mA}$ and $15 \mathrm{kV}$ ) and an eight channeltrons detector.

The carbon electrodes, with a maximum thickness of $4 \mathrm{~mm}$, were fixed in the aluminium container of a standard stainless steel multispecimen holder, by using a piece of double sided insulating tape. The samples were insulated to avoid differential charging between the conductive graphitic support and the insulating organic coating.

The pressure in the analysis chamber was about $1.010^{-6} \mathrm{~Pa}$. Photoelectrons were collected perpendicular to the sample surface. Analyses were performed in the hybrid lens mode (a combination of magnetic and electrostatic lenses); the analysed area was $700 \mu \mathrm{m} \times 300 \mu \mathrm{m}$. The pass energy of the hemispherical analyser was set at $160 \mathrm{eV}$ for the survey scan and 40 $\mathrm{eV}$ for narrow scans. In the latter conditions, the full width at half maximum (FWHM) of the $\mathrm{Ag} 3 \mathrm{~d}_{5 / 2}$ peak of a standard silver sample was about $0.9 \mathrm{eV}$.

Charge which was developed at the surface of these samples, insulated from the spectrometer, was stabilized by using an electron source mounted co-axially to the electrostatic lens column and a charge balance plate used to reflect electrons back towards the sample. The magnetic field of the immersion lens placed below the sample acts as a guide path for the low energy electrons returning to the sample. The electron source was operated at $1.9-2.1 \mathrm{~A}$ or $0.16 \mathrm{~A}$ filament current (depending on the filament type) and a bias of -1 . or $-1.21 \mathrm{eV}$. The charge balance plate was set between -3.5 and $-4.1 \mathrm{e} \mathrm{V}$.

The following sequence of spectra was recorded: survey spectrum, $\mathrm{C} 1 \mathrm{~s}, \mathrm{O} 1 \mathrm{~s}, \mathrm{~N} 1 \mathrm{~s}, \mathrm{Cl} 2 \mathrm{p}$, $S 2 p, P 2 p, N a 1 s$ and sometimes $B$ is and F 1s, then $C$ 1s again to check for charge stability as a function of time and the absence of degradation of the sample during the analyses. The $\underline{\mathbf{C}}-(\mathrm{C}, \mathrm{H})$ component of the $\mathrm{C} 1 \mathrm{~s}$ peak of carbon has been fixed to $284.8 \mathrm{eV}$ to set the binding energy scale.

Spectra were treated with the CasaXPS program (Casa Software Ltd., UK). Peaks, excepted C 1s, were decomposed with a Gaussian/Lorentzian (70/30) product function and using constraints that will be described in results. The $\mathrm{C}$ 1s peak decomposition would be hazardous due to the presence of both graphitic asymmetric $\mathrm{C}-(\mathrm{C}, \mathrm{H})$ component and shake up, on the one hand, and typical organic carbon components at the surface, on the other hand.

Mole fractions were calculated using peak areas normalised on the basis of acquisition parameters after a linear background subtraction, experimental sensitivity factors and transmission factors (depending on kinetic energy, analyser pass energy and lens combination) provided by the manufacturer. Elemental mole fractions are provided, excluding hydrogen which is not detected by XPS.

\section{Results and discussion}

Functionalization of carbon electrodes was achieved by electrochemical reduction of aryldiazonium salts. This method of carbon surface modification was developed by Pinson and co-workers and creates a strongly bound layer of substituted phenyl groups on the surface[25].

In the present work, aminophenyl and carboxyphenyl diazonium salts were used. After surface functionalization, laccase was immobilized, either by adsorption or by covalent grafting via an amide bond formation (Scheme 1)

\section{Here Scheme 1}

\subsection{Immobilization of laccase on aminophenyl groups functionalized electrodes 3.1.1. Functionalization of the carbon electrodes}

Nitrophenyl diazonium reduction was first performed by a single potential cycle between 0.8 and $-0.2 \mathrm{~V} / \mathrm{SCE}$ at $50 \mathrm{mVs}^{-1}$. The obtained voltammograms (supplementary information Fig. S1) showed a clear diazonium reduction peak around $0.5 \mathrm{~V} / \mathrm{SCE}$, in accordance to the 
results previously reported ones in the literature[24] [39]. The charge due to the reduction process was calculated by integration of the cathodic peak area of the cyclic voltammogram and the average coverage based on the geometrical area of the electrode was deduced. This value corresponds to $4.4 \times 10^{-8}$ moles $\mathrm{cm}^{-2}$, for 4 -nitrophenyldiazonium deposition. Thus, the coverage was found to be more than one order of magnitude higher than the theoretical value for a compact monolayer of phenyl rings, $1.35 \times 10^{-9} \mathrm{~mol} \mathrm{~cm}^{-2}[40]$ or $6.7 \times 10^{-10} \mathrm{~mol} / \mathrm{cm}^{2}$ [41], or of nitrophenyl group :1.2 $\times 10^{-9} \mathrm{~mol} / \mathrm{cm}^{2}$ [42] as a consequence of a multilayer grafting on the carbon surface[43].

The 4-nitrophenyl groups of the modified electrode were reduced in a second step by cyclic voltammetry in 9:1 water/ethanol solution to a mixed layer of hydroxylaminophenyl and aminophenyl groups (Scheme 1). Hydroxylaminophenyl grafted groups gave rise to a welldefined redox process at $-0.3 \mathrm{~V} / \mathrm{SCE}$ observed by cyclic voltammetry[44] [45]. By integration of the hydroxyaminophenyl reduction or oxidation waves and of the voltammetric reduction wave of the initial nitro groups, the coverage of amino and hydroxylamine groups was estimated as $1.2 \pm 0.2 \times 10^{-8} \mathrm{~mol} \mathrm{~cm}^{-2}$ and $5.5 \pm 1.3 \times 10^{-9} \mathrm{~mol} \mathrm{~cm}^{-2}$, respectively, calculated considering the geometrical area of the electrode[45]. These values are consistent with the ones reported in previous works on nitro phenyl diazonium salts reduction: $3.13 \times 10^{-8} \mathrm{molcm}^{-2}$ on polished PGE [46] and $3.6 \times 10^{-8} \mathrm{~mol} \mathrm{~cm}^{-2}$ on roughly polished graphite carbon[21]. Such a high amino density could be attributed to aryl-aryl polymerization and consequently, to a multilayer formation, as evidenced by TEM imaging by Kariuki[43,47]. In addition, it can be noticed that this reduced nitro groups coverage is lower than that calculated from the current density during the nitrophenyl diazonium salt reduction process, thus indicating that only a fraction of the grafted 4-nitrophenyl groups are electrochemically reduced under our experimental conditions. Another explanation could result from the cleavage of a fraction of the substituted phenyl group from the carbon electrode surface $[38,39,40]$.

The surface chemical composition of the grafted layers and the enzyme coverage were further studied by X-ray photoelectron spectroscopy on the 4-substituted phenyl modified carbon electrodes. Fig. 1 shows the N1 s core level spectra for a bare graphite, after 4nitrophenyl grafting and after reduction of the nitro groups. The corresponding $\mathrm{O} / \mathrm{C}$ and N/C ratios are reported in Table 1.

Table 1: Atomic surface composition of bare and functionalized electrodes and laccase surface coverage after enzyme immobilization on the functionalized electrode.

\begin{tabular}{|c|c|c|c|c|c|}
\hline & & \multicolumn{2}{|c|}{ Mole fraction (XPS) } & \multicolumn{2}{|c|}{ Laccase coverage \% } \\
\hline $\begin{array}{c}\text { Functionalization } \\
\text { type }\end{array}$ & $\begin{array}{c}\text { Laccase } \\
\text { immobilisation } \\
\text { method }\end{array}$ & $\mathrm{N} / \mathrm{C}$ & $\mathrm{O} / \mathrm{C}$ & $\begin{array}{l}\text { From XPS } \\
\text { measurements }\end{array}$ & $\begin{array}{l}\text { From activity } \\
\text { measurements }\end{array}$ \\
\hline $\begin{array}{c}\text { No } \\
\text { functionalization }\end{array}$ & No laccase & 0.001 & 0.022 & \\
\hline $\mathrm{C}-\Phi-\mathrm{NO}_{2}$ & No laccase & 0.036 & 0.057 & \\
\hline After nitro group & No laccase & $0.045 \pm 0.005^{\mathrm{c}}$ & $0.051 \pm 0.004$ & \\
\hline
\end{tabular}




\begin{tabular}{|c|c|c|c|c|c|}
\hline \multirow{2}{*}{$\mathrm{C}-\Phi-\mathrm{NH}_{2}{ }^{\mathrm{a}}$} & Adsorption & 0.079 & 0.102 & 64 & $33 \pm 3$ \\
\hline & $\begin{array}{l}\text { Covalent } \\
\text { grafting }\end{array}$ & 0.079 & 0.102 & 64 & $49 \pm 4$ \\
\hline $\begin{array}{c}\mathrm{C}-\Phi-\mathrm{COOH}^{\mathrm{b}} \\
\begin{array}{c}\text { With presynthesized } \\
\text { diazonium }\end{array}\end{array}$ & No laccase & 0.007 & 0.058 & & \\
\hline \multirow{3}{*}{$\begin{array}{c}\mathrm{C}-\Phi-\mathrm{COOH}^{\mathrm{C}} \\
\text { With in situ } \\
\text { generated diazonium }\end{array}$} & No laccase & $0.012 \pm 0.001$ & $0.114 \pm 0.002$ & & \\
\hline & Adsorption & $0.016 \pm 0.001$ & $0.080 \pm 0.001$ & 17 & $10 \pm 3$ \\
\hline & $\begin{array}{l}\text { Covalent } \\
\text { grafting }\end{array}$ & $0.050 \pm 0.005$ & $0.131 \pm 0.010$ & $45 \pm 2$ & $43 \pm 2$ \\
\hline
\end{tabular}

a : Amino groups were formed upon electrochemical reduction of nitrophenyl groups (deposited by cyclic voltammetry from nitrobenzenediazonium grafting)

$\mathrm{b}$ : From synthesized carboxybenzne diazonium; c: From in situ generated diazonium

c : Error was calculated from two independent XPS analysis of two different samples

The surface of bare graphite contains only traces of nitrogen. The $\mathrm{N} 1 \mathrm{~s}$ signal after 4nitrophenyl grafting shows three components with a binding energy at about 400, 403 and and $406 \mathrm{eV}$. The main component at about $400 \mathrm{eV}$ could correspond to amine $\left(-\mathrm{NH}_{2}\right)$ groups. The components at $\sim 403 \mathrm{eV}$ and $\sim 406 \mathrm{eV}$ are attributed to nitrogen in azobenzene $(-\mathrm{N}=\mathrm{N}$ )[48] and nitro groups $\left(-\mathrm{NO}_{2}\right)[49]$, respectively. The electrochemical reduction of diazonium groups into amine was previously reported by Ortiz et al[44], especially when the phenyl groups are reduced by cycling the potential compared to upon constant polarization. However, reduction of the nitro groups to amino groups during the electrografting procedure should be ruled out because the grafting was performed at a potential for which the electrochemical reduction of nitro groups cannot occur. Another explanation for the presence of amine groups could be the reduction of nitro groups induced by XPS analysis conditions, as suggested by Baranton and Belanger [35]

After nitro group reduction by potential cycling between -0.2 and $-1.4 \mathrm{~V}$, a significant enhancement of the amine component at $400 \mathrm{eV}$ with respect to the azobenzene component at $403 \mathrm{eV}$ was observed (Fig. 1 curve 3). An additional component was observed near 405 $\mathrm{eV}$, which could be attributed to the hydroxyamino groups. A $70 \%$ reduction of the nitrogen fraction attributed to $\mathrm{NO}_{2}$ groups was observed after the electrochemical reduction process (Table 1), which is in agreement with the one deduced from charge density measurement as discussed above.

Here Fig. 1

\subsubsection{Immobilization of laccase on aminophenyl functionalised carbon}

Covalent immobilisation of laccase on the functionalized electrode was performed by formation of amide bonds between the amino groups of the electrode surface and the carboxylic groups exposed on the enzyme surface activated by a mixture of both carbodiimide (EDC) and N-hydroxysuccinimide (NHS) (see materials and methods Section). As a control experiment, laccase was also only adsorbed to the same type of functionalised graphite surface in the absence of any EDC/NHS activation.

After laccase immobilisation, successive washings of the electrode with $10 \mathrm{mM}$ phosphate buffer $\mathrm{pH} 7$ until no activity could be detected in the rinsing solution were performed. This 
procedure allowed to remove all weakly adsorbed enzyme and usually led to a decrease of 3-4 folds of the laccase activity on the surface electrode.

\section{Here Fig. 2}

The highest activity, namely $42.5 \pm 2.5 \mathrm{mUcm}^{-2}$ (Fig. 2) was obtained when the diazonium salt was grafted by performing one unique potential cycle. This protocol was thus used throughout the work. For this electrodeposition protocol, the activity on the electrode was higher for covalent coupling than for adsorption whereas the amount of adsorbed or covalently immobilized laccase was not significantly different when the electrode was functionalized with slightly different methods, e.g. performing two potential cycling instead of one or using a fixed potential. It could thus be concluded that activity of immobilized enzyme was hardly affected by the laccase immobilization method, that could be mostly driven by favourable electrostatic interactions between positively charged laccase whose isoelectrical point is about 3 , and the negatively charged functionalized electrode surface. Indeed, assuming that $\mathrm{pKa}$ of the amino groups on the functionalized electrode is around 6.9, as measured by capacitance experiments for a monolayer of 4-aminothiophenyl groups on gold[50], half of the amine groups are protonated, and the electrode surface has a strong positive charge that should favour adsorption of laccase at $\mathrm{pH} 7$.

After laccase immobilisation, $\mathrm{O} / \mathrm{C}$ and N/C ratios, measured by XPS, (Table 1) significantly increased by almost two fold at the electrodes surface. The presence of the biomolecule was confirmed on $\mathrm{C}$ 1s core level spectra by the presence of two shoulders at $\sim 286.5 \mathrm{eV}$ and $\sim 288.5 \mathrm{eV}$ (Fig. 3) typical for carbon bound to $\mathrm{N}$ and/or $\mathrm{O}$ in proteins (alcohol or amine functions, and amide from the peptidic bond, respectively[51].

Here Fig. 3

An estimation of the laccase coverage level was performed fromcN/C XPS ratios. The hypothesis of a continuous layer was discarded because the thickness of the layer was always lower than the protein lowest dimension. Nevertheless, a denaturation of the laccase in contact with the carbon surface could contribute to a thickness decrease. The hypothesis of a discontinuous monolayer[51] with a thickness equal to $5 \mathrm{~nm}$, corresponding to one of the laccase dimensions $\left(7 \times 5 \times 5 \mathrm{~nm}^{3}\right)$ [21] was retained and computed surface coverage values are reported in Table 1. It is not possible to make the distinction between adsorption and covalent grafting on $\mathrm{NH}_{2}$ functionalized electrodes according to the $\mathrm{N} / \mathrm{C}$ XPS ratios which are close together, so the estimated laccase coverage is $64 \%$ for both.

On the other hand, density of immobilized enzyme could be estimated to $1.5 \mathrm{pmol} \mathrm{cm}{ }^{-2}$ and $2.4 \mathrm{pmol} \mathrm{cm}$-2 of active enzyme after adsorption and covalent grafting, respectively, from activity measurements of the immobilized enzyme (Fig. 2). The surface coverage was thus around $33 \pm 5 \%$ for adsorbed laccase and $49 \pm 4 \%$ for covalent grafting. The coverage estimated from XPS measurements is thus 1.3 and 1.8 times higher than the coverage estimated from enzyme activity for adsorption and covalent grafting, respectively. This discrepancy could be the result of the partial denaturation of the enzyme during the immobilisation process on the surface, leading to an underestimation of the amount of immobilized protein deduced from activity measurements. It should also be mentioned that the modelization results depend on both the parameters choice as well as the limited depth analysed by XPS (at most $10 \mathrm{~nm}$ ), thus also explaining the disparity between modelization and experimental results.

Here Fig. 4

The maximal dioxygen reduction current density measured by chronoamperometry at 0.2 V/SCE (Fig. 4) on an amino functionalized electrode after laccase covalent immobilization 
was $12.5 \mu \mathrm{Acm}^{-2}$. However, a very poor reproducibility of the measured current intensity was observed. When measuring the current by CV, a large capacitive signal superimposed with the faradic current. Control experiments were carried out without any EDC or NHS, laccase being only immobilized by adsorption on the amino functionalized surface. No dioxygen reduction current was detected in these conditions. In order to assess whether this low current could be the result of the electrode passivation during the functionalization process, electrodeposition was performed with a lower diazonium salt concentration, i.e. $2 \mathrm{mM}$ instead of $5 \mathrm{mM}$. It was thus expected to decrease the surface film thickness and favour the electron transfer. However, no increase of the dioxygen biocatalytic reduction was observed.

Dioxygen reduction current generation via direct electron transfer between laccase and amino groups functionalized electrode has been previously reported for laccase immobilized via EDC/NHS coupling $[19,41,44]$. In particular, Vaz Dominguez and coworkers reported a current around $150 \mu \mathrm{Acm}^{-2}$ from cyclic voltammetry, which was ten times higher than obtained in the present work in spite of similar experimental conditions for both , e.g. phenyl diazonium salt electrodeposition and laccase covalent immobilisation methods on a roughly polished graphite electrode. The authors interpreted this high current as a result of the affinity between the enzyme and aniline group on the surface, the latter derivatives being good substrates of laccase. The rational of this work was that preferential orientation of the active site of laccase towards the electrode favoured the electron transfer by minimizing the distance between electron acceptor copper site and the surface.

The calculation of the surface concentration $\Gamma$ for electroactive laccase, i.e. properly oriented for DET reactions between carbon and the copper ions, led to an estimated enzyme coverage of $0.5 \mathrm{pmolcm}^{-2}$, using $\mathrm{A}_{\text {geom }}$ of the graphite disk and assuming an exchange of four electrons per electroactive molecule of the redox enzyme[52]. This value is low compared to the surface concentration of active laccase, namely $2.4 \mathrm{pmolcm}^{-2}$, calculated from activity measurements and suggests that less $20 \%$ of the enzyme showed an accurate orientation for DET. This could explain the low dioxygen biocatalyzed current measured in the present work.

\section{Here Fig. 5}

In an attempt to improve laccase immobilization in a suitable orientation for DET, we took advantage of the presence of some glycosidic moities in the vicinity of the reducing substrate active site of the enzyme (Fig. 5). Indeed the analysis of the primary sequence of laccase IIIb from $T$. versicolor, the one used in this work, indicates six potential glycosylation sites. The 3D structure resolution on the basis of crystallographic data[23] clearly indicated glycosylation on four sites among the six putative glycosylation sites based on the primary sequence, including asparagines 208, 333 and 436, whose amide carbon is located from 11 to $15 \AA$ from the T1 copper active site. Our assumption was that after the enzyme orientation on the electrode by adsorption thanks to the affinity between the aniline group on the electrode and the T1 active site, it could be covalently linked in the same position via its nearby oxidised glycosidic moities and the amino groups on the carbon surface via a Schiff base formation (scheme 2).

\section{Here Scheme 2}

Such an immobilisation strategy by covalent coupling between the aldehyde groups resulting from the enzyme oxidation and the amino groups on the electrode led to oxidized laccasecoated electrodes that generated higher current, with a density as $78 \pm 5 \mu \mathrm{Acm}^{-2}$ (Fig. 4). For comparison, experiments using oxidized laccase immobilised via an amide bound formation using EDC/NHS also improved the current response with respect to the unmodified laccase up to $51 \pm 2 \mu \mathrm{Acm}^{-2}$, as measured by chronoamperometry at $0.2 \mathrm{~V}$, thus outrunning the current with unmodified laccase five times. 
However, it should be noticed that whatever the laccase form (oxidized or not) or immobilisation method on amino functionalised electrode, the results were not satisfactory reproducible. Indeed, no current was detected for more than half of the amino modified electrodes. Such a poor reproducibility could result from the reduction step of the nitro groups in acidic solutions, leading to a film shrinkage and indentation or pores formation on the surface, as evidenced by AFM imaging [45]. Consequently, we decided to functionalize the carbon surface by the same diazonium electroreduction method but using another functional group, i.e. a carboxylic group in para position that does not require any further modification following the diazonium reduction (scheme 1B).

\subsection{Chemical modification of electrodes with carboxyphenyl groups}

Two experimental functionalization procedures were used for diazonium grafting step. The first one used pre-synthesized 4-carboxylic diazonium salt. The second method consisted of in situ generation of 4-carboxybenzoic diazonium salt 4-carboxy aniline. In both cases, the obtained voltammograms (SI Fig. 2) showed a diazonium reduction at -0.24 and $0.21 \mathrm{~V} / \mathrm{SCE}$ for the 4-carboxyphenyl one, in accordance to the results previously reported in the literature[35]. The grafted phenyl groups density after diazonium reduction calculated from the voltamogramms was $2.3 \pm 0.510^{-8} \mathrm{molcm}^{-2}$ for the diazonium in situ generation and $1.2 \pm$ $0.5 \times 10^{-8} \mathrm{~mol} / \mathrm{cm}^{2}$ when a presynthesized diazonium salt was electroreduced, that is about two times lower than the coverage calculated for 4-nitrophenyl electrodeposition. This lower coverage could result from the modification of the solvent used in electrodeposition experiments. Indeed 4-carboxyphenyl diazonium was grafted in an aqueous electrolyte in acidic conditions. The benzoic acid diazonium salt being positively charged whereas the bare carbon is very hydrophobic, its adsorption, and therefore its grafting is altered compared to 4anitrophenyl diazonium dissolved in acetonitrile. In the case of electrode modified from nitrobenzenediazonium reduction, Downard et al. [53] have reported that films prepared from aqueous solutions were more blocking to ET and thinner that those prepared from acetonitrile solution. This was attributed to solvation effects, interactions between diazonium and carbon surface, and to differences in the radical attack in the two solvents. Consequently, the benzoic acid layer on the electrode surface should be thinner than that observed for aniline grafted groups.

Here Fig. 6

Carboxylic group density was further assessed through the capacity of carboxylic group to complex the positively charged toluidine blue dye and was evaluated to $1.1 \pm 0.2 .10^{-8} \mathrm{~mol}$ $\mathrm{cm}^{-2}$ and $1.9 \pm 0.2 .10^{-8} \mathrm{molcm}^{-2}$ for pre-synthesized and in situ generated 4-carboxybenzene diazonium, respectively. These results are in good agreement with the grafted phenyl densities obtained from reduction current for both grafting procedures, namely $1.2 \pm 0.5 .10^{-8}$ molcm ${ }^{-2}$ and $2.3 \pm 0.5 \cdot 10^{-8}$ molcm $^{-2}$. The better grafting efficiency of the in situ diazonium generation method was further confirmed by molar surface ratios O/C deduced from XPS measurements (Table 1), namely $0.114 \pm 0.002$ compared to 0.058 for the presynthesized diazonium.

The XPS O 1s core level spectrum of the functionalised carbon (Fig. 6 ) was consistent with a surface coverage of carboxylic groups, both $\mathrm{C}-\mathrm{O}$ and $\mathrm{C}=\mathrm{O}$ components showing similar intensity. The $\mathrm{N} 1 \mathrm{~s}$ spectrum shows the presence of a significant amount of nitrogen on the surface, namely N/C $0.012 \pm 0.001$ instead of 0.001 for the bare polished carbon, maybe resulting from physical adsorption of some diazonium groups. After enzyme immobilisation by adsorption, the $\mathrm{N} / \mathrm{C}$ ratio slightly increased to 0.016 whereas the $\mathrm{O} / \mathrm{C}$ ratio decreased from 0.114 to 0.080 (Table 1), with a $O$ 1s peak (Fig. 6) very similar to that of the functionalised electrode before enzyme adsorption. In contrast, when laccase was covalently grafted, the presence of the enzyme is clearly confirmed by the presence of a $N$ 1s component at $\sim 400 \mathrm{eV}$ assigned to the amine/amide groups, as well as by the presence of a 
$\mathrm{O}$ 1s component at $\sim 532 \mathrm{eV}$ assigned to $\mathrm{C}=\mathrm{O}$ mostly from the peptidic links. Consistently, the $C$ 1s spectrum showed an enhancement of the shoulders at $\sim 286.5$ and $\sim 288.5 \mathrm{eV}$ attributed to functions present in proteins (including peptidic bond).

Here Fig. 7

The low enzyme adsorption compared to the covalent immobilization was corroborated by laccase activity measurements. Indeed covalently linked laccase activity was higher than that for adsorbed laccase, namely $36.5 \pm 1.3 \mathrm{mUcm}^{-2}$ and $8.5 \pm 2.8 \mathrm{mUcm}^{-2}$, respectively, in case of in situ generated 4-carboxyphenyl diazonium, which corresponds to $43 \pm 2 \%$ and $10 \pm 3 \%$ of surface coverage. These results were very close to those obtained from XPS modelling data. Indeed the laccase coverage after covalent grafting was calculated to about 2.5 times higher than by adsorption, $45 \%$ and $17 \%$, respectively. Similar tendency was found also with an electrode functionalized with pre-synthesized diazonium (Fig. 7).

Such low laccase adsorption could be explained by unfavourable electrostatic interactions at $\mathrm{pH} 7$ between the unprotonated carboxylic groups on the carbon surface (pKa of surface grafted 4-carboxyphenyl about 2.8 [54]) and the negatively charged enzyme (isoelectric point of laccase is around 3).

Comparison with modified electrodes obtained by electroreduction of acidic solution containing the dissolved 4-carboxyphenyl salt showed that the amount of laccase activity was higher when the diazonium was in situ generated for both immobilisation methods, the gap being the most significant for the covalent immobilisation method with a 4 fold increase of the activity when the enzyme was covalently grafted compared to only adsorbed.

Here Fig. 8

Cyclic voltammograms showed (Fig. 8) that electroenzymatic reduction of $\mathrm{O}_{2}$ takes place at redox potentials below $0.6 \mathrm{~V} / \mathrm{SCE}$, which is in agreement with the redox potential of the copper at T1 laccase active site, namely $0.790-0.241=0.55 \mathrm{~V}$ vs. SCE[55] and reached a pseudo-plateau around $0.2 \mathrm{~V} / \mathrm{SCE}$. The current intensity due to the biocatalysed reduction of dioxygen was calculated from the difference of current obtained at $0.2 \mathrm{~V} / \mathrm{SCE}$ in the presence and in the absence of dissolved dioxygen in the solution for the same electrode.

After functionalization of the electrode by presynthetized diazonium, followed by laccase immobilisation, the currents at $0.2 \mathrm{~V}$ were $14.5 \pm 5.0 \mu \mathrm{Acm}^{-2}$ after covalent immobilisation using EDC/NHS and $2.6 \pm 1.0 \mu \mathrm{Acm}^{-2}$ after laccase adsorption, respectively. A significant scattering of the data was observed. Higher and more reproducible currents were obtained in case of graphite functionalized with in situ generated diazonium namely, $25.1 \pm 7.0 \mu \mathrm{Acm}^{-2}$ for

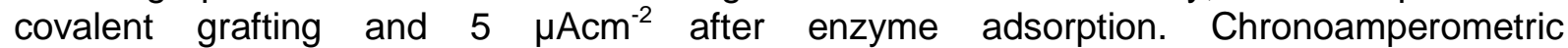
measurements at $0.2 \mathrm{~V}$ gave similar currents for covalent grafting, namely $28 \pm 6 \mu \mathrm{Acm}^{-2}$.

When laccase was deposited directly on the electrode by simple physical adsorption, the detected current was five fold lower than that obtained by covalent immobilization, which is in line with the measured activity ratios in the same conditions and could be an indirect indication that the covalent immobilisation method did not reduce the electroactivity of the enzyme compared to the adsorbed one.

It was noticed that the current density at $0.2 \mathrm{~V}$ vs. SCE does not depend on the electrode rotation speed between 500 and 1500 rpm (data not shown), which could result from the absence of dioxygen mass transfer limitation. The current was thus likely to be proportional to the turnover number $\mathrm{k}$ of the immobilised laccase and to the enzyme coverage on the electrode[56]. The maximal theorical value of the current density $\dot{j}_{\max }$ therefore can be estimated according to equation 1:

$j_{\max }=\frac{i_{\max }}{S_{\text {electrode }}}=\frac{n e k}{S_{\text {laccase }}}$ 
With $S_{\text {electrode }}=0.39 \mathrm{~cm}^{2}$ the electrode surface, $S_{\text {laccase }}$ the surface occupied by one laccase molecule on the electrode, $\mathrm{n}$ the number of electrons involved in the electronic transfer with the electrode and e the electron charge $\left(-1.610^{-19} \mathrm{C}\right)$. Assuming that the catalytic constant $\mathrm{k}_{\text {cat }}$ of laccase in solution (300 s$~ s^{-1}$ with Abu62, a blue dye as a substrate[57]) is a suitable approximation for the turnover number $\mathrm{k}$ of the immobilised laccase and knowing that laccase dimensions are $70 \times 50 \times 50 \AA^{3}[23]$, the maximal current density $j_{\max }$ is around 200 $\mu \mathrm{Acm}^{-2}$.

It can therefore be likely that the currents reported above, i.e. less than $30 \mu \mathrm{Acm}^{-2}$, could be theoretically be improved. This was observed when immobilizing oxidized laccase. In that case, the observed current density was $141 \pm 37 \mu \mathrm{Acm}^{-2}$ and $122 \pm 9 \mu \mathrm{Acm}^{-2}$, by covalent coupling or adsorption respectively, namely five and twenty five times higher than the ones obtained with unmodified laccase using the same protein grafting procedure with EDC/NHS. Assuming that the activity of immobilized laccase is representative of the immobilized quantity and knowing that laccase activity on the surface remained unchanged around 30 $\mathrm{mU} / \mathrm{cm}^{2}$ (Fig. 7) for oxidized or unmodified laccase, such a current increase could thus suggest that the DET was favoured thanks to laccase oxidation, as a result of a better accessibility of the T1 copper because of a selected orientation of the protein on the surface.

When immobilising oxidised laccase on 4-carboxyphenyl electrodes, the obtained current densities were very closed whatever the immobilisation method, i.e. covalent coupling or adsorption, which was not the case for the unmodified laccase (Fig 9). This result was confirmed for different grafting protocols inversing the deposition order between the activation compounds EDC/NHS and the laccase on the surface (Fig 9), or the duration the protein and/or EDC/NHS were allowed to react on the surface before rinsing (data not shown). The highest current measured by cyclic voltammetry $\left(177 \pm 25 \mu \mathrm{Acm}^{-2}\right)$ was obtained after laccase deposition on the electrode for two hours, removal of the enzyme drop and addition of a mixture of $4.5 \mathrm{mM} \mathrm{EDC}$ and $11 \mathrm{mM} \mathrm{NHS}$, diluted two fold compared to the standard protocol.

Here Fig. 9

Yet as we have previously demonstrated with 4-aminophenyl surfaces that the covalent coupling method using EDC/NHS was more efficient than adsorption as an immobilization method, it could suggest that laccase affinity for the carboxylic surface was higher after enzyme oxidation and overcame unfavourable electrostatic interactions.

\section{Conclusion}

In this work, we have functionalized graphite surfaces by the aryldiazonium electroreduction method to allow the subsequent immobilization of laccase, either by adsorption or by covalent grafting via two different functional groups: amino or carboxylic ones. Functionnalization of the electrode with carboxylic groups followed by covalent grafting of the enzyme led to significantly higher dioxygen reduction current than electrode functionalization with amino groups, in spite of very similar activity of the immobilized enzyme. In addition, estimation of the protein surface coverage from XPS measurements showed that the quantity of immobilized protein was higher with amino functionalized electrode. These results could indicate that the orientation of the enzyme is more favourable to an efficient electron transfer when the protein is bonded via its five lysine groups rather than randomly grafted via its forty five carboxylic groups. It was showed for the first time that laccase oxidation led to the improvement of the current density up to $160 \mu \mathrm{Acm}^{-2}$ on an electrode functionalized with carboxylic groups, namely a five times increase compared to the unmodified laccase using 
the same covalent grafting protocol. Conversely to what was observed with unmodified laccase, covalent grafting of the oxidized enzyme did not lead to an improvement of the dioxygen current density compared to that obtained with adsorbed protein. We can put forward the hypothesis that the enzyme could be more favourably orientated on the electrode surface when oxidized, thus leading to an improved direct electron transfer and that covalent anchoring of the enzyme on the surface via its oxidized glycosidic groups could further amplify this improvement.,

\section{Acknowledgements}

The financial supports from the French Ministry of Research and Higher Education (MESR), from the Belgian National Foundation for Scientific research (FNRS) and from BELSPO are gratefully acknowledged. 


\section{References}

1. Barton SC, Kim H-H, Binyamin G, Zhang Y, Heller A (2001) Electroreduction of O2 to Water on the "Wired" Laccase Cathode $\uparrow$. The Journal of Physical Chemistry B 105: 11917-11921.

2. Bullen RA, Arnot TC, Lakeman JB, Walsh FC (2006) Biofuel cells and their development. Biosensors and Bioelectronics 21: 2015-2045.

3. Osman MH, Shah AA, Walsh FC (2011) Recent progress and continuing challenges in biofuel cells. Part I: Enzymatic cells. Biosensors and Bioelectronics 26: 3087-3102.

4. Cracknell JA, Vincent KA, Armstrong FA (2008) Enzymes as Working or Inspirational Electrocatalysts for Fuel Cells and Electrolysis. Chemical Reviews 108: 2439-2461.

5. Willner I, Yan YM, Willner B, Tel-Vered R (2009) Integrated Enzyme-Based Biofuel Cells-A Review. Fuel Cells 9: 7-24.

6. Suraniti E, Tsujimura S, Durand F, Mano N (2013) Thermophilic biocathode with bilirubin oxidase from Bacillus pumilus. Electrochemistry Communications 26: 41-44.

7. Frank Davis, Higson SPJ (2007) Biofuel cells-Recent advances and applications. Biosensors and Bioelectronics 22 1224-1235.

8. Prévoteau A, Courjean O, Mano N (2010) Deglycosylation of glucose oxidase to improve biosensors and biofuel cells. Electrochemistry Communications 12: 213-215.

9. Barton SC, Gallaway J, Atanassov P (2004) Enzymatic Biofuel Cells for Implantable and Microscale Devices. Chemical Reviews 104: 4867-4886.

10. Heller A, Feldman B (2008) Electrochemical Glucose Sensors and Their Applications in Diabetes Management. Chemical Reviews 108: 2482-2505.

11. Amir L, Tam TK, Pita M, Meijler MM, Alfonta L, et al. (2008) Biofuel Cell Controlled by Enzyme Logic Systems. Journal of the American Chemical Society 131: 826-832.

12. Moehlenbrock MJ, Minteer SD (2008) Extended lifetime biofuel cells. Chemical Society Reviews 37: 1188-1196.

13. Cinquin P, Chantal Gondran, Fabien Giroud, Simon Mazabrard, Aymeric Pellissier, et al. (2010) A Glucose BioFuel Cell Implanted in Rats. PloS One 5.

14. Zebda A, Chantal Gondran, Alan Le Goff, Michael Holzinger, Cinquin P, et al. (2011) Mediatorless high-power glucose biofuel cells based on compressed carbon nanotubeenzyme electrodes. nature communication.

15. Reuillard B, Le Goff A, Agnès C, Zebda A, Holzinger M, et al. (2012) Direct electron transfer between tyrosinase and multi-walled carbon nanotubes for bioelectrocatalytic oxygen reduction. Electrochemistry Communications 20: 19-22.

16. Zebda A, Cosnier S, J.-P. Alcaraz, M. Holzinger, A. Le Goff, et al. (2013) Single Glucose Biofuel Cells Implanted in

Rats Power Electronic Devices. Nature SCIENTIFIC REPORTS 3: 1-5.

17. Cosnier S, Le Goff A, Holzinger M (2014) Towards glucose biofuel cells implanted in human body for powering artificial organs: Review. Electrochemistry Communications 38: 19-23.

18. Pankratov D, Blum Z, Suyatin DB, Popov VO, Shleev S (2014) Self-Charging Electrochemical Biocapacitor. ChemElectroChem 1: 343-346.

19. Pankratov D, Falkman P, Blum Z, Shleev S (2014) A hybrid electric power device for simultaneous generation and storage of electric energy. Energy \& Environmental Science 7: 989-993.

20. Reuillard B, Le Goff A, Agnes C, Holzinger M, Zebda A, et al. (2013) High power enzymatic biofuel cell based on naphthoquinone-mediated oxidation of glucose by 
glucose oxidase in a carbon nanotube 3D matrix. Physical Chemistry Chemical Physics 15: 4892-4896.

21. Vaz-Dominguez C, Campuzano S, Rüdiger O, Pita M, Gorbacheva M, et al. (2008) Laccase electrode for direct electrocatalytic reduction of $\mathrm{O} 2$ to $\mathrm{H} 2 \mathrm{O}$ with highoperational stability and resistance to chloride inhibition. Biosensors and Bioelectronics 24: 531-537.

22. Pita M, Gutierrez-Sanchez C, Olea D, Velez M, Garcia-Diego C, et al. (2011) High Redox Potential Cathode Based on Laccase Covalently Attached to Gold Electrode. The Journal of Physical Chemistry C 115: 13420-13428.

23. Bertrand T, Jolivalt C, Briozzo P, Caminade E, Joly N, et al. (2002) Crystal Structure of a Four-Copper Laccase Complexed with an Arylamine: Insights into Substrate Recognition and Correlation with Kinetics $\uparrow,+$. Biochemistry 41: 7325-7333.

24. Allongue P. , M. Delamar, B. Desbat, O. Fagebaume, R. Hitmi, et al. (1997) J Am Chem Soc 119

25. Belanger D, Pinson J (2011) Electrografting: a powerful method for surface modification. Chemical Society Reviews 40: 3995-4048.

26. Boland S, Foster K, Leech D (2009) A stability comparison of redox-active layers produced by chemical coupling of an osmium redox complex to pre-functionalized gold and carbon electrodes. Electrochimica Acta 54: 1986-1991.

27. Downard AJ, Garrett DJ, Tan ESQ (2006) Microscale Patterning of Organic Films on Carbon Surfaces Using Electrochemistry and Soft Lithography. Langmuir 22: 1073910746.

28. Benjamin C, Christophe A. Marquette, Blum LJ (2005) Diazonium-Protein Adducts for Graphite Electrode Microarrays Modification: Direct and Addressed Electrochemical Immobilization. J Am Chem Soc 127: 18328-18332.

29. Pellissier M, Barrière F, Downard AJ, Leech D (2008) Improved stability of redox enzyme layers on glassy carbon electrodes via covalent grafting. Electrochemistry Communications 10: 835-838.

30. Blanford CF, Foster CE, Heath RS, Armstrong FA (2009) Efficient electrocatalytic oxygen reduction by the 'blue' copper oxidase, laccase, directly attached to chemically modified carbons. Faraday Discussions 140: 319-335.

31. Barton SC, Pickard M, Vazquez-Duhalt R, Heller A (2002) Electroreduction of O2 to water at $0.6 \mathrm{~V}$ (SHE) at $\mathrm{pH} 7$ on the 'wired' Pleurotus ostreatus laccase cathode. Biosensors and Bioelectronics 17: 1071-1074.

32. Binyamin G, Cole J, Heller A (2000) Mechanical and Electrochemical Characteristics of Composites of Wired Glucose Oxidase and Hydrophilic Graphite. Journal of The Electrochemical Society 147: 2780-2783.

33. Bertrand T, Jolivalt C, Caminade E, Joly N, Mougin C, et al. (2002) Purification and preliminary crystallographic study of Trametes versicolor laccase in its native form. Acta Crystallographica D58: 319-321.

34. Bourdillon C, Delamar M, Christophe Demaille, Rachid Hitmi, Moiroux J, et al. (1992) Immobilization of glucose oxidase on a carbon surface derivatized by electrochemical reduction of diazonium salts. J Electroanal Chem 336 113-123.

35. Baranton S, Belanger D (2005) Electrochemical Derivatization of Carbon Surface by Reduction of in Situ Generated Diazonium Cations. J Phys Chem B 109: 24401-24410.

36. Chollet C, Chanseau C, Brouillaud B, Durrieu MC (2007) RGD peptides grafting onto poly(ethylene terephthalate) with well controlled densities. Biomolecular Engineering 24: 477-482.

37. Chaga G (1994) A general method for immobilization of glycoproteins on regenerable immobilized metal-ion carriers: application to glucose oxidase from Penicillium 
chrysogenum and horseradish peroxidase. Biotechnology and applied biochemistry 20: 43-53.

38. Wolfenden B, Wilson $\mathrm{R}$ (1982) radical cations as a reference chromogens in kinetics studies of one electron transfer reactions: pulse radiolyse studies of 2,2'-azinobis-(3ethylbenzthiazoline-6-sulphonate. Journal of chemical society Perkin transaction 2: 805-812.

39. Delamar M, Hitmi R, Pinson J, Saveant JM (1992) J Am Chem Soc 114: 5883-5884

40. Pinson J, Podvorica F (2005) Attachment of organic layers to conductive or semiconductive surfaces by reduction of diazonium salts. Chemical Society Reviews 34: 429-439.

41. Breton T, Bélanger D (2008) Modification of Carbon Electrode with Aryl Groups Having an Aliphatic Amine by Electrochemical Reduction of In Situ Generated Diazonium Cations. Langmuir 24: 8711-8718.

42. Liu Y-C, McCreery RL (1995) Reactions of Organic Monolayers on Carbon Surfaces Observed

with Unenhanced Raman Spectroscopy. J Am Chem SOC 117: 11254-11259.

43. Kariuki JK, McDermott MT (2001) Formation of Multilayers on Glassy Carbon Electrodes via the Reduction of Diazonium Salts. Langmuir 17: 5947-5951.

44. Ortiz B, Saby C, Champagne GY, Bélanger D (1998) Electrochemical modification of a carbon electrode using aromatic diazonium salts. 2. Electrochemistry of 4-nitrophenyl modified glassy carbon electrodes in aqueous media. Journal of Electroanalytical Chemistry 455: 75-81.

45. Brooksby PA, Downard AJ (2005) Multilayer Nitroazobenzene Films Covalently Attached to Carbon. An AFM and Electrochemical Study. The Journal of Physical Chemistry B 109: 8791-8798.

46. Alonso-Lomillo MA, Rüdiger O, Maroto-Valiente A, Velez M, Rodríguez-Ramos I, et al. (2007) Hydrogenase-Coated Carbon Nanotubes for Efficient H2 Oxidation. Nano Letters 7: 1603-1608.

47. Kariuki JK, McDermott MT (1999) Nucleation and Growth of Functionalized Aryl Films on Graphite Electrodes. Langmuir 15: 6534-6540.

48. Zhang W-W, Ren X-M, Li H-F, Lu C-S, Hu C-J, et al. (2002) Study on Self-Assembled Monolayers of Functionalized Azobenzene Thiols on Gold: XPS, Electrochemical Properties, and Surface-Enhanced Raman Spectroscopy. Journal of Colloid and Interface Science 255: 150-157.

49. NIST (2012). X-ray photoelectron spectroscopy Database 20 Version 41

50. Pita M, Shleev S, Ruzgas T, Fernández VM, Yaropolov AI, et al. (2006) Direct heterogeneous electron transfer reactions of fungal laccases at bare and thiol-modified gold electrodes. Electrochemistry Communications 8: 747-753.

51. Dupont-Gillain CC, Jacquemart I (2003) Patterned collagen layers on polystyrene: direct probing using AFM in the adhesion mapping mode. Surface Science 539: 145-154.

52. Ressine A, Vaz-Domínguez C, Fernandez VM, Lacey ALD, Laurell T, et al. (2010) Bioelectrochemical studies of azurin and laccase confined in three-dimensional chips based on gold-modified nano-/microstructured silicon. Biosensors and Bioelectronics 25 1001-1007.

53. Brooksby PA, Downard AJ (2004) Electrochemical and Atomic Force Microscopy Study of Carbon Surface Modification via Diazonium Reduction in Aqueous and Acetonitrile Solutions. Langmuir 20: 5038-5045. 
54. Saby C, Ortiz B, Champagne GY, Bélanger D (1997) Electrochemical Modification of Glassy Carbon Electrode Using Aromatic Diazonium Salts. 1. Blocking Effect of 4Nitrophenyl and 4-Carboxyphenyl Groups. Langmuir 13: 6805-6813.

55. Solomon EI, Sundaram UM, Machonkin TE (1996) Multicopper Oxidases and Oxygenases. Chem Rev 96: 2563-2605.

56. Pershad HR, Duff JLC, Heering HA, Duin EC, Albracht SPJ, et al. (1999) Catalytic Electron Transport in Chromatium vinosum [NiFe]-Hydrogenase: Application of Voltammetry in Detecting Redox-Active Centers and Establishing That Hydrogen Oxidation Is Very Fast Even at Potentials Close to the Reversible H+/H2 Value $\uparrow$. Biochemistry 38: 8992-8999.

57. Enaud E, Trovaslet M, Naveau F, Decristoforo A, Bizet S, et al. (2011) Laccase chloride inhibition reduction by an anthraquinonic substrate. Enzyme and Microbial Technology 49: 517-525. 
Figure and scheme captions

Scheme 1: Functionalization methods of the graphite electrodes by diazonium salts electrodeposition, followed by laccase covalent grafting after carboxylic groups activation by EDC/NHS. (A) using presynthesized 4-nitrophenyl diazonium salts. (B) by in situ synthesis of diazonium

Scheme 2: Oxidized laccase immobilization procedure on amino functionalized carbon electrode

Figure 1: N 1s XPS spectra of carbon graphite electrode (1) bare, (2) after nitrophenyl diazonium grafting, (3) after nitro groups reduction

Figure 2: Unmodified laccase activity on the electrode for three different 4-aminophenyl diazonium electrografting methods and two immobilization methods (black adsorption, slashed grey covalent grafting). Conditions: $5 \mathrm{mM}$ diazonium grafted by cyclic voltammetry at $50 \mathrm{mVs}^{-1}$ or chronoamperometry at $0.25 \mathrm{~V} / \mathrm{SCE}$ during $30 \mathrm{~s}$, followed by the nitro groups reduction by cyclic voltammetry, one cycling from 0 to $-1.4 \mathrm{~V} / \mathrm{SCE}$ at $10 \mathrm{mVs}^{-1}$.

Figure 3 : C 1s XPS spectra of (1) the amino functionalized surface, (2) after adsorption of laccase, (3) after covalent immobilisation of laccase. (Intensity scale adjusted in order that peak maxima coincide).

Figure 4: Chronoamperometric measurement at $E=0.2$ V/SCE before and after bubbling air into the electrolyte. Laccase immobilized on the 4-amino functionalized electrode. (Black line : unmodified laccase covalently grafted using EDC/NHS ; dotted line : oxidized laccase covalently grafted without any coupling agent via a Schiff base formation; dashed line: oxidized laccase covalently grafted using EDC/NHS

Figure 5 : Tridimensional structure of laccase (from pdb file 1KYA). Protein backbone in white; copper ions: blue spheres; carbohydrates: grey and red spheres

Figure 6: $\mathrm{O} 1 \mathrm{~s}, \mathrm{~N}$ 1s and $\mathrm{C}$ 1s XPS spectra of 4 benzoic acid funtionalized electrode. The corresponding diazonium salt was generated in situ in the electrolytic cell from 4 -amino benzoic acid $5 \mathrm{mM}$. (1) electrode without laccase, (2) electrode with adsorbed laccase, (3) electrode with covalently immobilised laccase. C 1s: intensity scale adjusted in order that peak maxima coincide.

Figure 7 : Activity of immobilized laccase (oxidized or not) on 4-benzoic acid functionalized electrode using two deposited diazonium salt synthesis methods. (Black) immobilisation by adsorption. (Grey): immobilisation by covalent grafting

Figure 8: Cyclic voltammograms recorded at $10 \mathrm{mV} / \mathrm{s}$ for a 4-benzoic acid functionalized electrode after laccase covalent immobilization using EDC/NHS. Solution consists of 100 $\mathrm{mM} \mathrm{NaClO}_{4}$, in $50 \mathrm{mM}$ acetate buffer $\mathrm{pH}$ 4.2. Solid line: under nitrogen atmosphere. Dotted line: solution saturated with air. The electrode surface area is $0.39 \mathrm{~cm}^{2}$ 
Figure 9 : Biocatalytic currents densities obtained with unmodified and oxidized laccase. The current is recorded at $\mathrm{E}=0.2 \mathrm{~V} / \mathrm{SCE}$ at an electrode functionalized by electrodeposition of 4-benzoic acid diazonium salt synthesized in situ. (Black) laccase immobilized by adsorption. (Grey) laccase immobilized by covalent grafting. Grafting protocol 1: EDC/NHS mixture on electrode surface for 2 hours, then addition of laccase. Protocol 2: laccase solution first on the surface for 2 hours, then addition of the mixture EDC/NHS 
A<smiles>CC(c1ccc([N+](=O)[O-])cc1)c1ccc([N+](=O)[O-])cc1</smiles><smiles>CCC(C)c1ccc(NO)cc1</smiles>

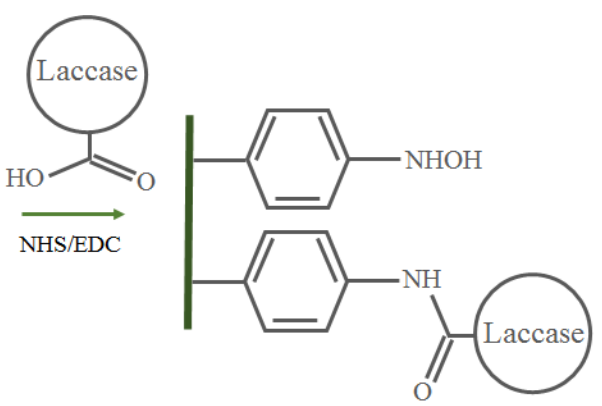

\section{B}

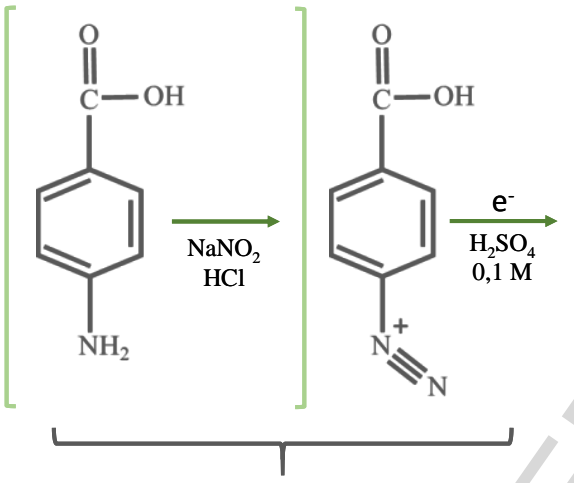

In situ synthesis of diazonium

\section{Scheme 1}

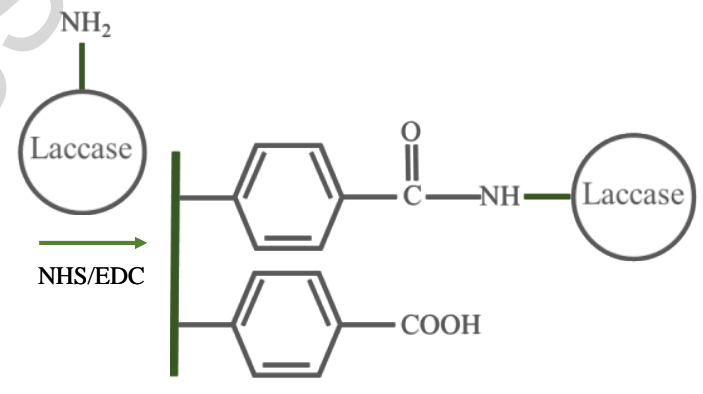




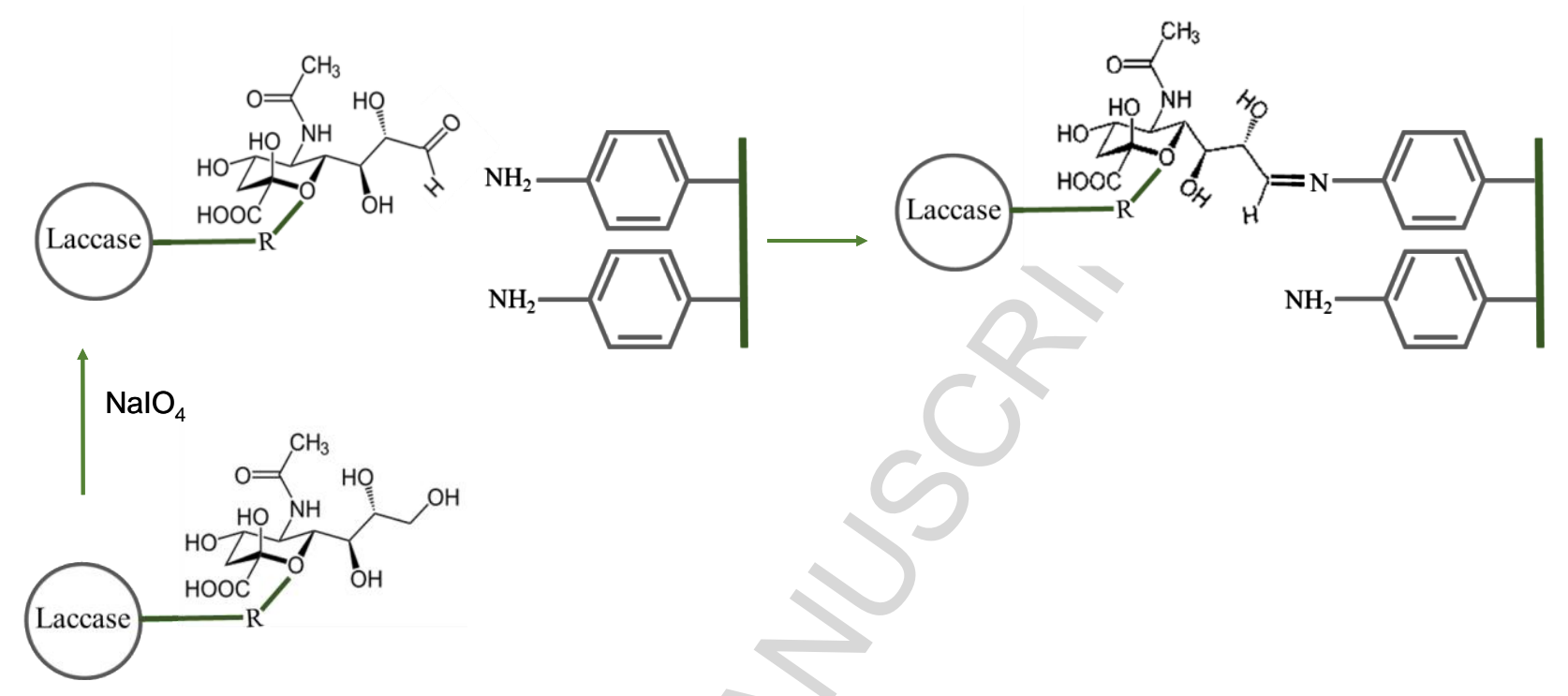

Scheme 2 


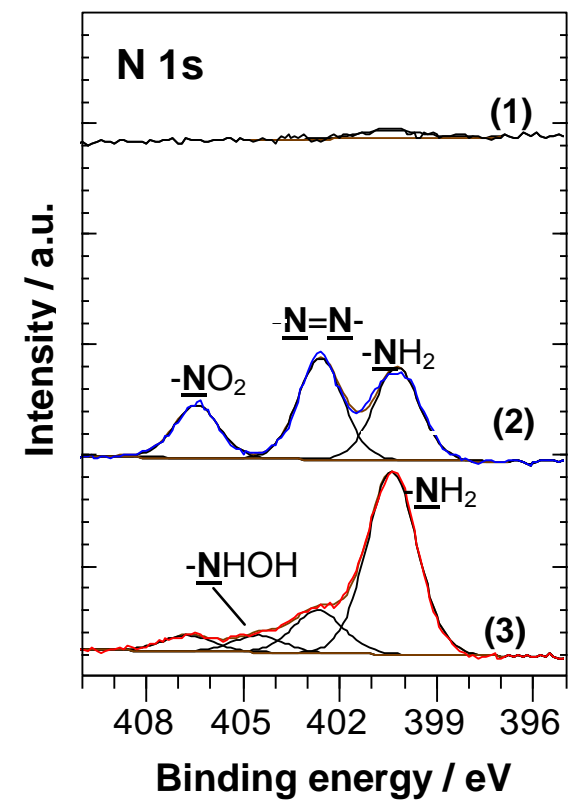

Figure 1 


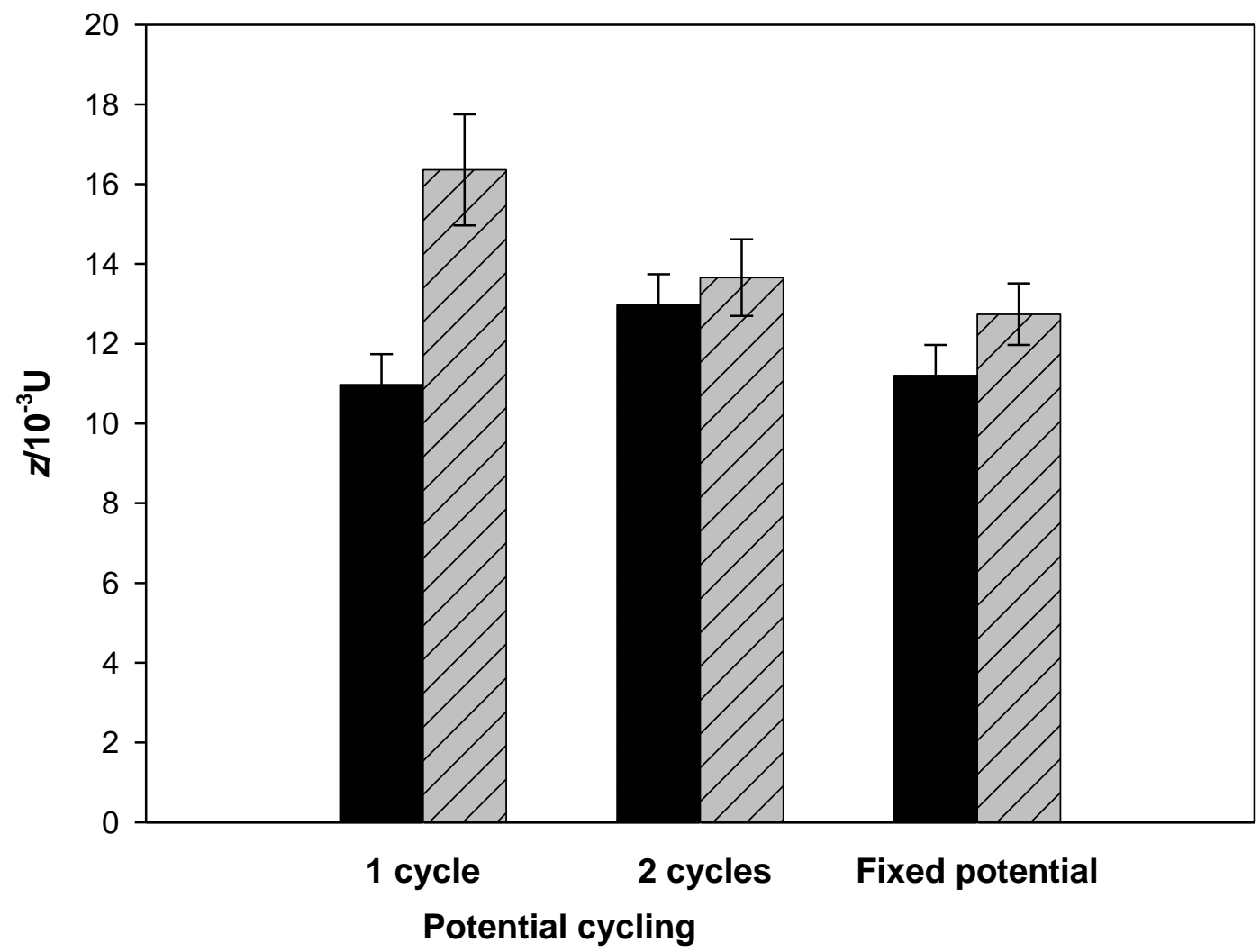

Figure 2 


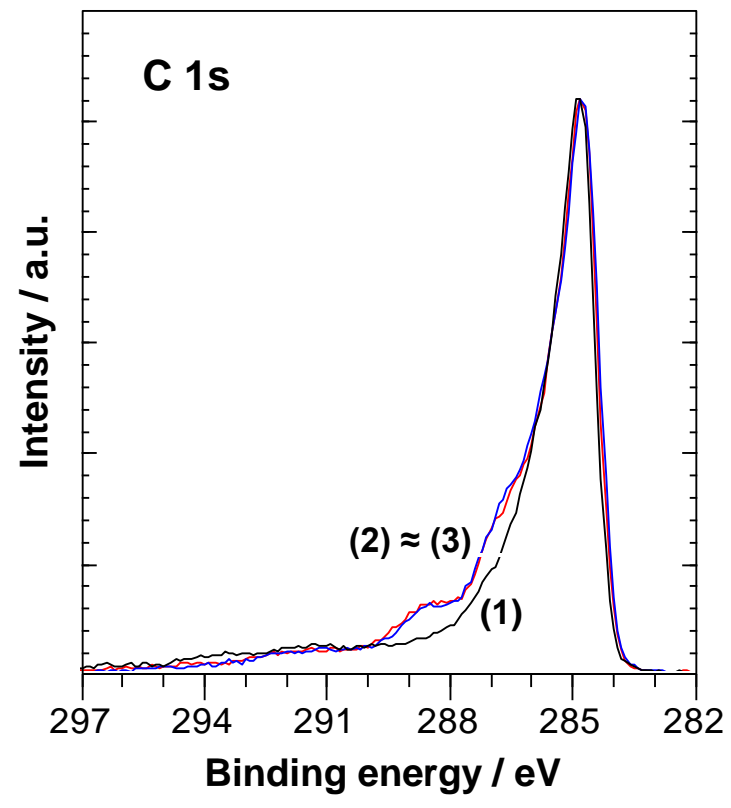

Figure 3 


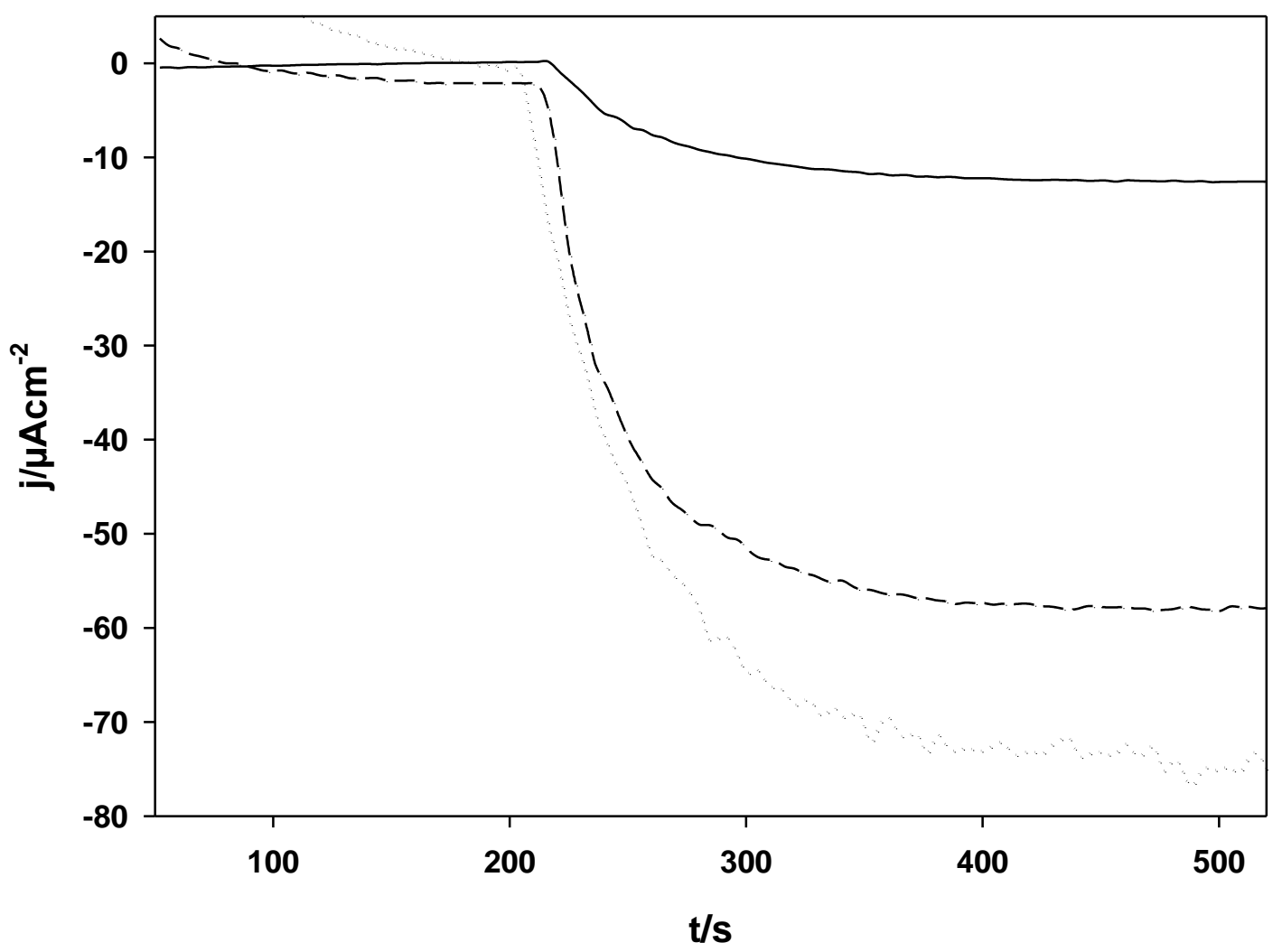

Figure 4 


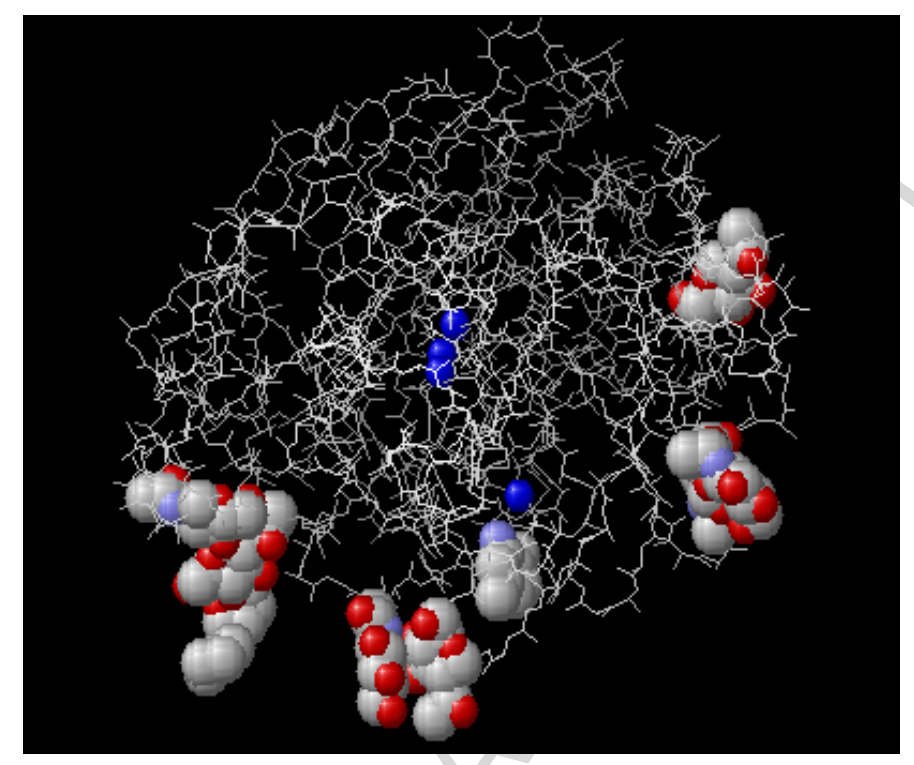

Figure 5 


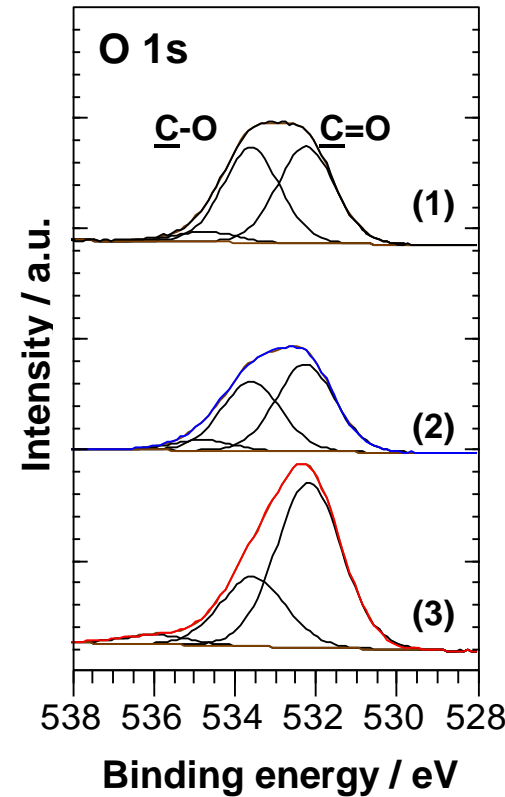

Binding energy / eV
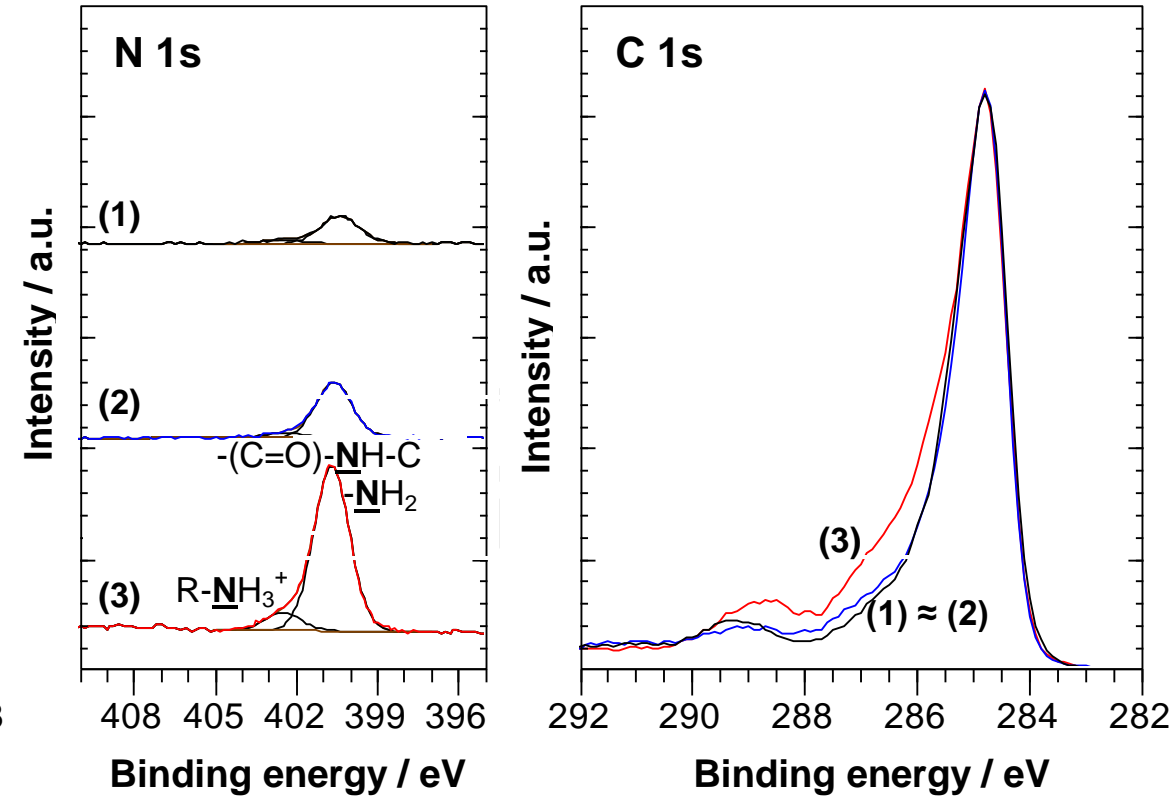

Figure 6 


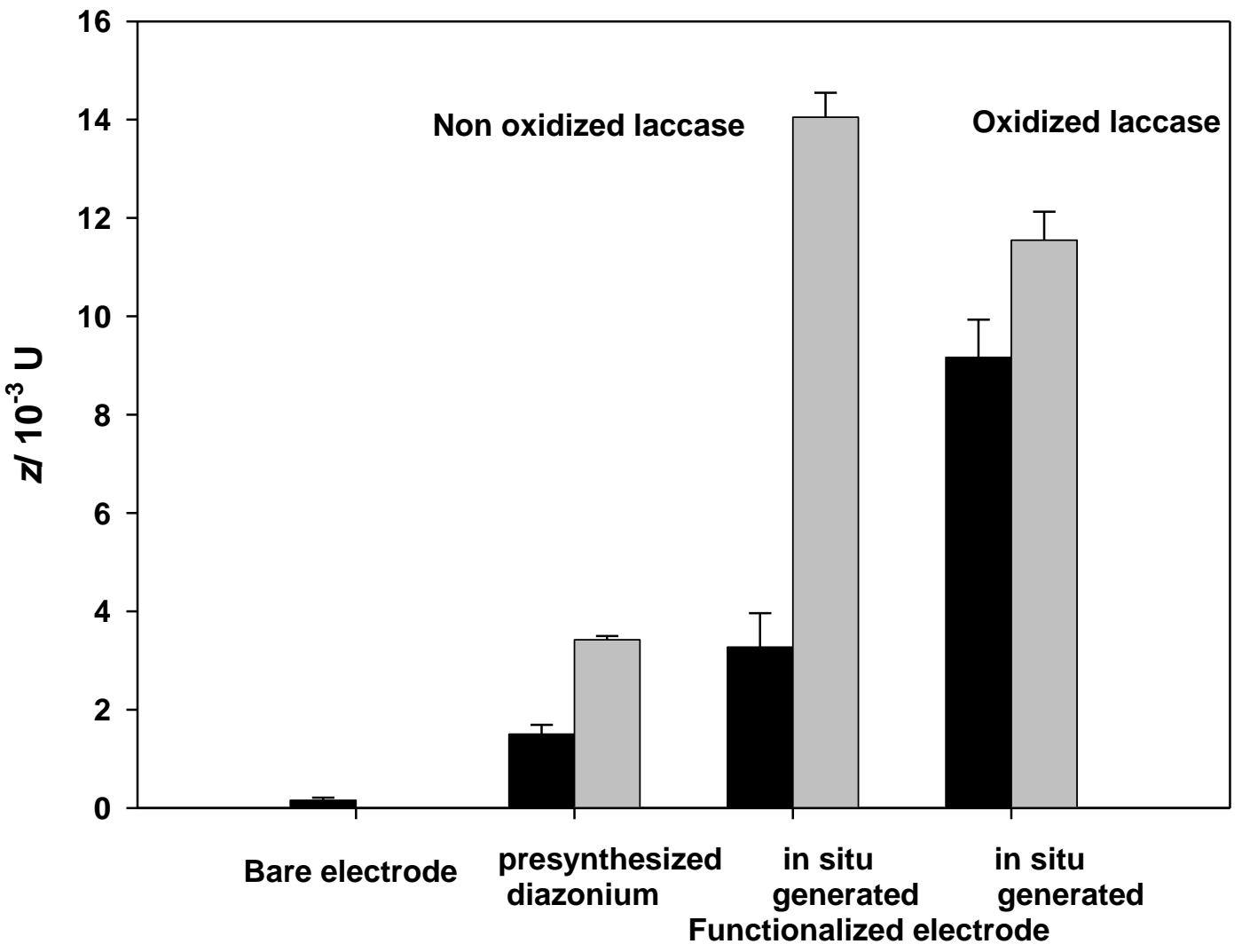

Figure 7 


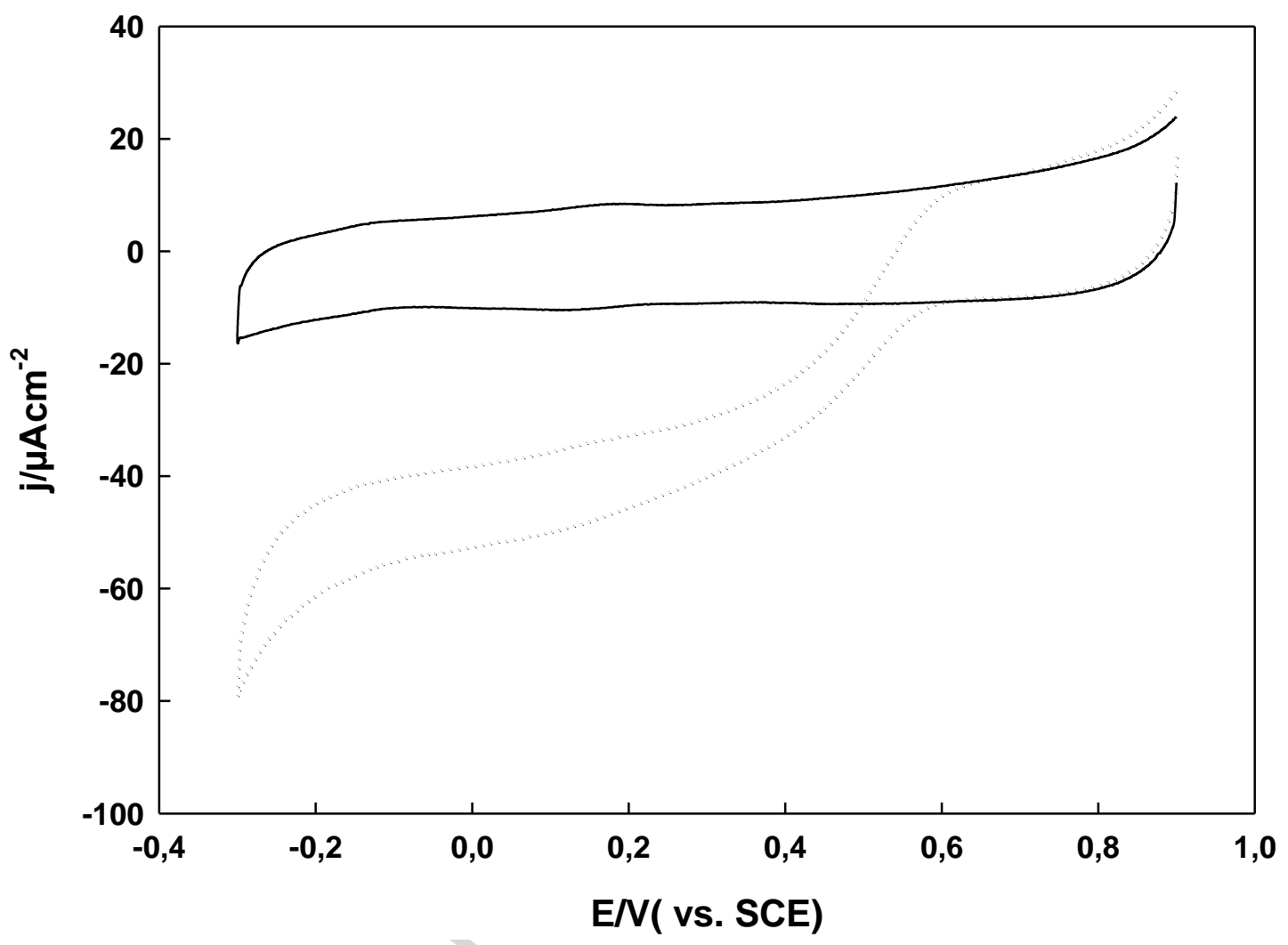

Figure 8 


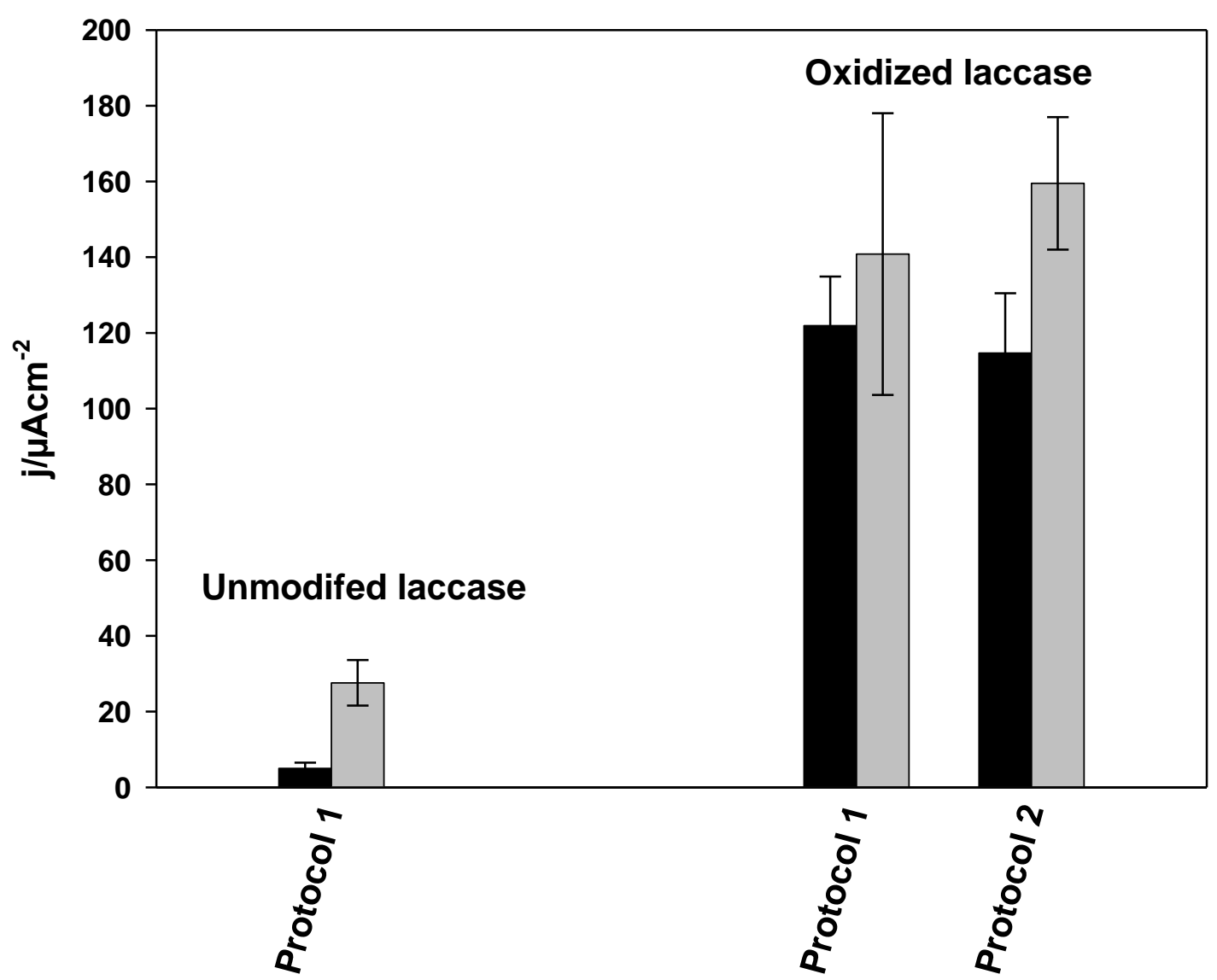

Figure 9 


\section{Vitae}

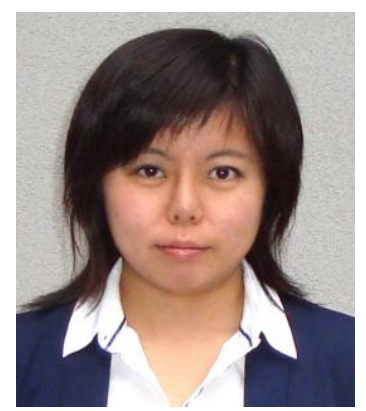

Meihui ZHENG was born in Jilin, China. She graduated from Northeast Normal University in Chanchun (China) in 2005. She received her Master from Université Paris 7 in 2009. She prepared her Ph.D. from 2009 at École nationale supérieure de chimie de Paris working with Dr. Claude JOLIVALT and obtained her Ph.D in 2012. Her Ph. D research concerns the biofuel cell, particularly the development of laccase cathode for direct electron transfer.

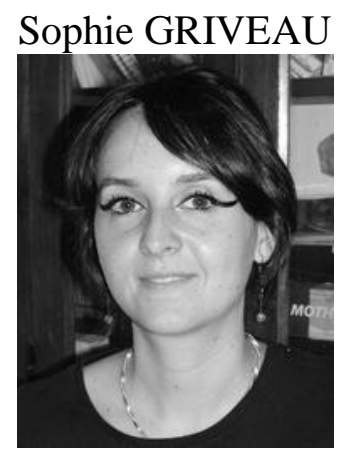

Sophie Griveau obtained her PhD in Analytical Chemistry from the University Pierre and Marie Curie, Paris, France0, in 2002. Since 2005 she is associate professor at Chimie ParisTech, Ecole Nationale Supérieure de Chimie de Paris, France. Her current research fields are focused on the conception of electrochemical microsensors for in vitro and in vivo detection of species of biological interest (such as nitric oxide) through the development of tailored electrode materials exhibiting electrocatalytic properties and/or selectivity towards targeted molecules. Her research is also devoted to the implementation of scanning electrochemical microscopy for the local scale functionalization and characterization of (bio)active surfaces.

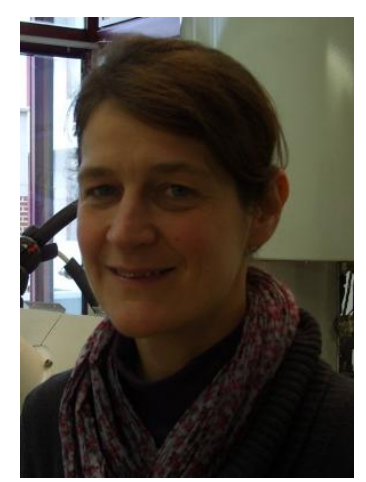

Prof. Christine Dupont-Gillain holds a $\mathrm{PhD}$ in agricultural sciences and bioengineering. She is currently lecturer at the Faculty of Bioengineering, Université catholique de Louvain (Belgium). She leads a research group specialized in the physical chemistry of biointerfaces. She is the author of about 80 papers and book chapters. 


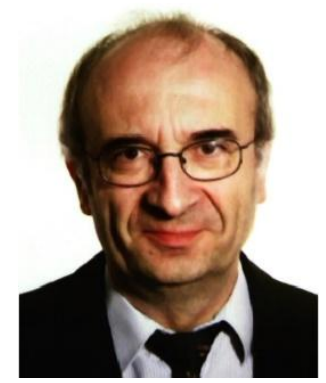

Michel J. Genet graduated in Sciences of Industrial Engineer at the High School of the Province of Liège (Belgium) in 1969. Until 2012 he was responsible for the Surface Characterisation Platform (SUCH) at Université catholique de Louvain (Belgium), where he developed a strong expertise in X-ray photoelectron spectroscopy (XPS). He is currently retired. $\mathrm{He}$ is co-author of several book chapters and 75 papers.

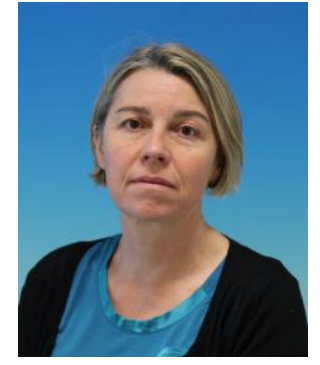

Claude Jolivalt obtained her PhD in Chemical Engineering at the Ecole des Mines de Paris and was assistant professor at the Ecole de Chimie de Paris from 1994 to 2012 where she has been in charge of the screening for antibacterial agents from natural and synthetic products and structure/activity relationship studies. She is currently professor at the University Pierre et Marie Curie in Paris (France). Her main research topic are heterogeneous biocatalysis with applications in synthesis of fine chemicals, energy or medicine and antimicrobial biomaterial engineering . 


\section{Supplementary Information}

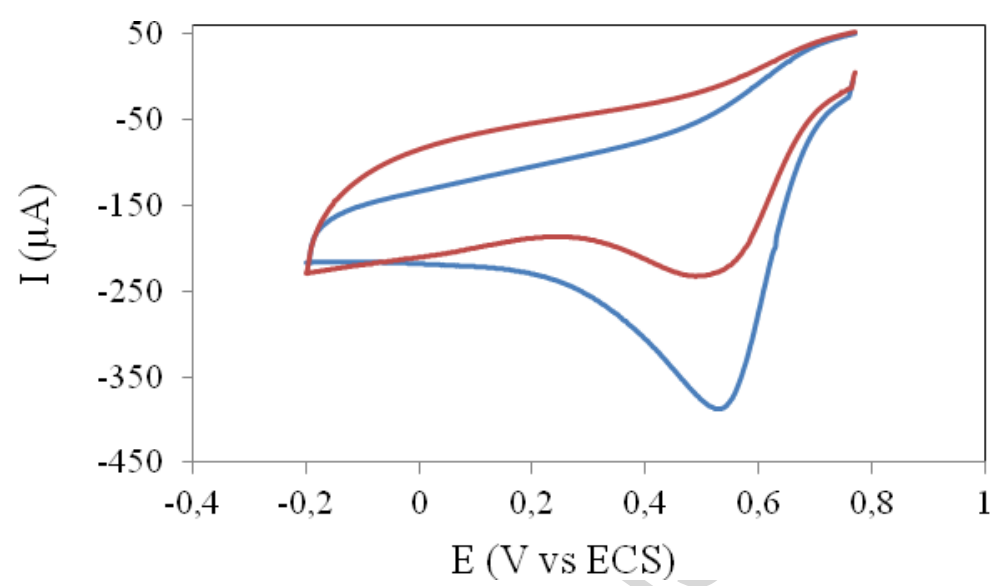

Figure $\mathbf{S 1}$ : Electroreduction of 4-nitrobenzene-diazonium tetrafluorobonate $\left(5.10^{-3} \mathrm{M}\right.$ in 0.1 $\mathrm{M} \mathrm{Bu}_{4} \mathrm{NBF}_{4}$ ) recorded at $50 \mathrm{mVs}^{-1}$ in acetonitrile. Blue curve: first cycling. Red curve: second cycling
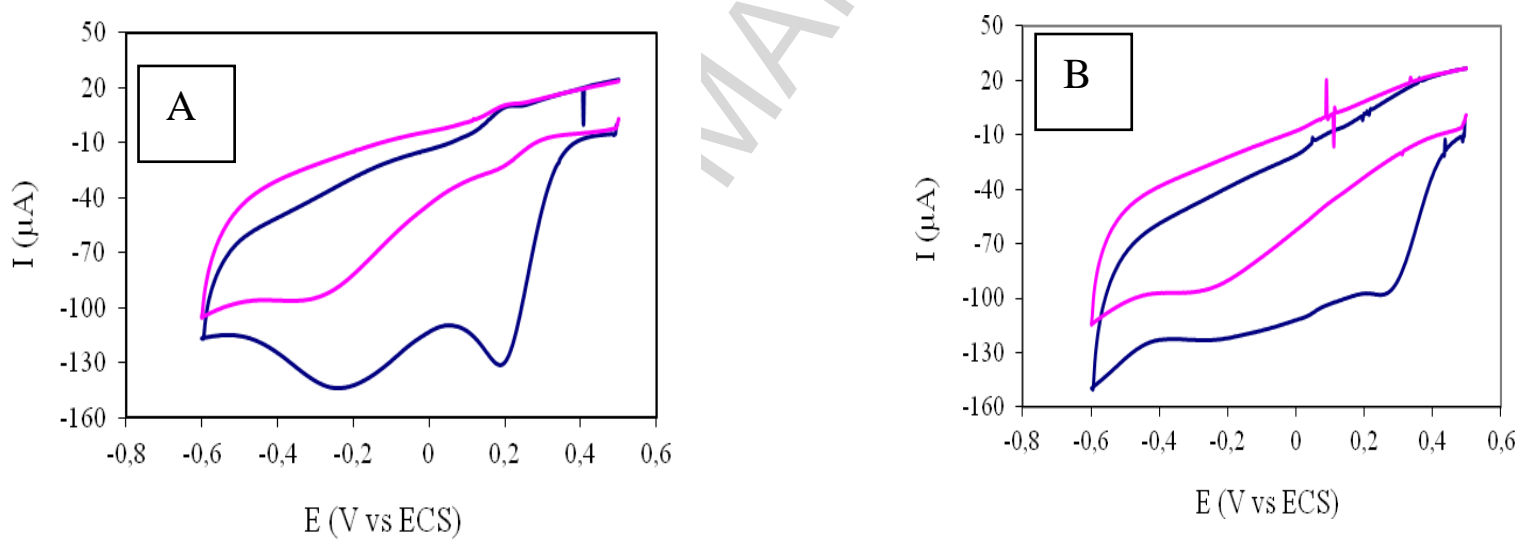

Figure S2 : Electroreduction of 4-carboxybenzène-diazonium. A) in situ generated from $5.10^{-3} \mathrm{M}$ 4-carboxy aniline. B) presynthetized, at $5.10^{-3} \mathrm{M}$. Blue curve: first cycling. Pink curve: second cycling. Cycling at $50 \mathrm{mVs}^{-1}$

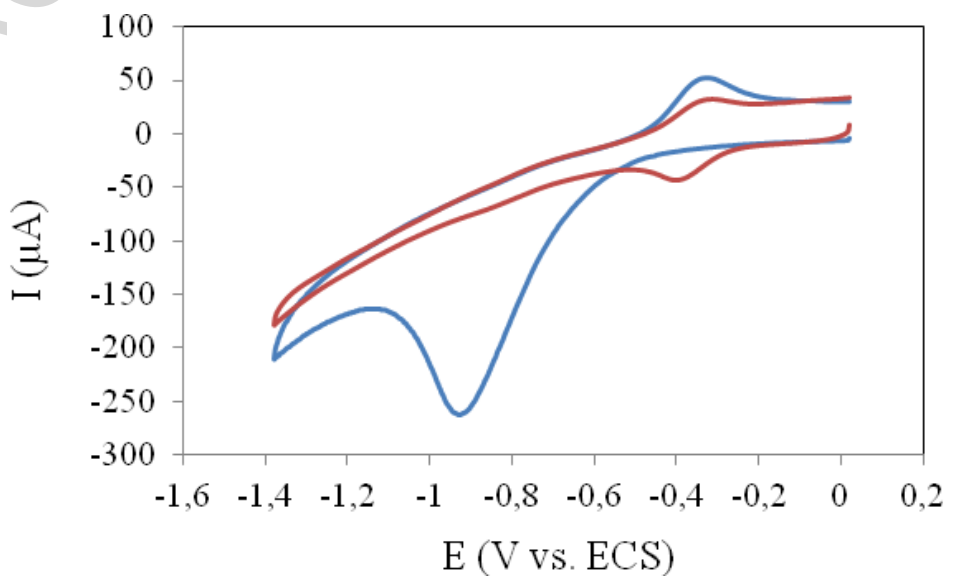

Figure S3: Electroreduction of grafted 4-nitrobenzene in EtOH : $\mathrm{H}_{2} \mathrm{O}(1: 9$, v/v) with $0.1 \mathrm{M}$ $\mathrm{KCl}$ as an electrolyte. Blue curve: first cycling. Red curve: second cycling. Cycling at 10 $\mathrm{mVs}^{-1}$ 
Highlights

- Laccase was immobilized on graphite functionalized by diazonium salt electroreduction

- XPS and activity measurements were used to quantify laccase surface coverage

- Coverage was four times higher for covalent grafting than for adsorption on carboxylic surface

- Oxidized laccase immobilization increased the current density 5- times

- Biocatalytic current with oxidized laccase reached $141 \pm 37 \mu \mathrm{Acm}^{-2}$ 